\title{
THE ROLE OF GERMLINE BRCA1 FOUNDER MUTATIONS AND SOMATIC TP53 MUTATIONS IN THE TRIPLE-NEGATIVE BREAST CANCER SUBTYPE
}

Summary of the Doctoral Thesis Speciality - Surgery 


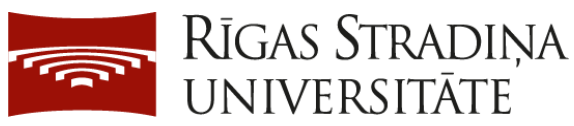

Jelena Maksimenko

\section{THE ROLE OF GERMLINE BRCAI FOUNDER MUTATIONS AND SOMATIC TP53 MUTATIONS IN THE TRIPLE-NEGATIVE BREAST CANCER SUBTYPE}

Summary of the Doctoral Thesis

Speciality - Surgery

Riga, 2014 
Doctoral Thesis was carried out in Pauls Stradins Clinical University hospital, Rīga Stradinš̌ University Department of Surgery and Oncology Institute, Riga, Latvia

Supervisors:

Dr. med., Associate Professor Genadijs Trofimovics,

Rīga Stradiņš University

Dr. biol., Professor Edvins Miklasevics,

Rīga Stradiņš University

Official reviewers:

Dr. med., Associate Professor Gunta Purkalne,

Rīga Stradinš̌ University

Dr. med., Assistant Professor Janis Eglitis, University of Latvia

Dr. biol., Janis Klovins, University of Latvia

Doctoral Thesis will defend on $8^{\text {th }}$ April 2014, at 15.00 during open meeting of Doctoral Council of Medicine, Rīga Stradiņš University, 16 Dzirciema Street, Lecture theatre Hippocrates.

Doctoral Thesis is available in the RSU Library and at RSU webpage: www.rsu.lv

The Doctoral Thesis was carrierd out with the support of the European Social Fund program "Project support for doctoral and post-doctoral studies in medical sciences"

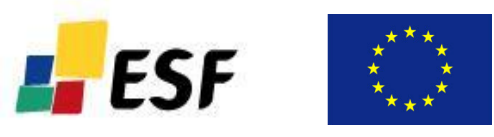

Secretary of the Promotional Council:

Dr. habil. med., Professor Janis Gardovkis 


\section{TABLE OF CONTENTS}

LIST OF ABBREVIATIONS ............................................................. 5

1. INTRODUCTION ......................................................................... 7

1.1. The aim of the research ............................................................... 9

1.2. Research objectives ..................................................................... 9

1.3. Scientific assumptions or working hypothesis ................................. 9

1.4. Scientific and practical novelty ...................................................... 10

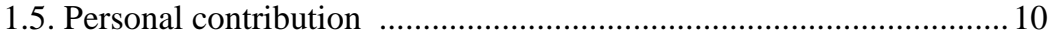

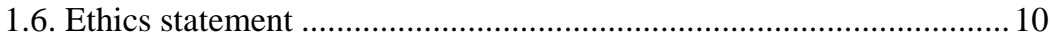

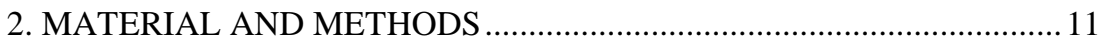

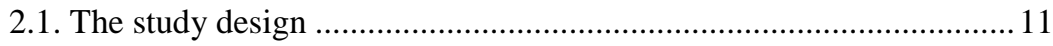

2.2. The pathological examination .......................................................... 14

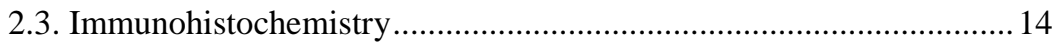

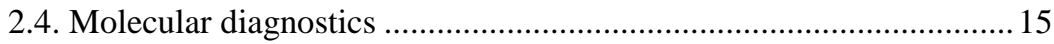

2.4.1. BRCA1/2 germline founder mutations ................................... 15

2.4.2. Detection of sporadic TP53 gene mutations ........................... 16

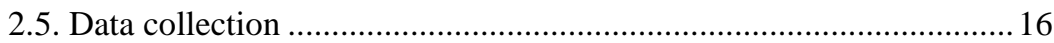

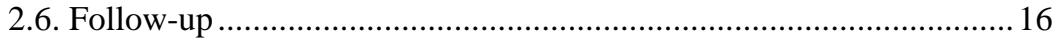

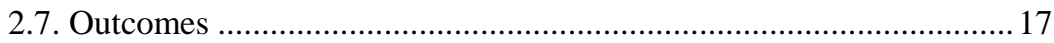

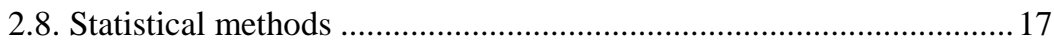

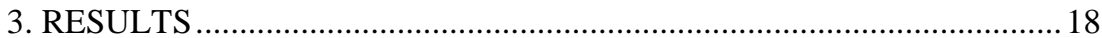

3.1. The clinicopathological characteristics and estimates of survival outcomes in the triple- negative luminal A, luminal B HER2 negative breast cancers............................................................................. 18

3.1.1. The clinicopathological characteristics of triple-negative,

luminal A, luminal B HER2 negative breast cancers......................... 18

3.1.2. Estimates of survival outcomes in the triple-negative,

luminal A, luminal B HER2 negative breast cancer. ........................2 20 
3.2. The clinicopathological characteristics and estimates of survival outcomes in the triple- negative breast cancer BRCAl mutation carriers and non-carriers

3.2.1. The clinicopathological characteristics of triple-negative breast cancer BRCAl mutation carriers and non-carriers

3.2.2. Estimates of survival outcomes in the triple-negative

BRCAl carriers and non-carriers. 26

3.3. Sporadic TP53 mutations in the triple-negative breast cancer. 29

3.3.1. Spectrum of TP53 sporadic mutations in the triple-negative breast cancer BRCAl germline mutations non-carriers and carriers

3.3.2. The association between $T P 53$ sporadic mutation $\mathrm{s}$ and clinicopathological characeteristics in the triple-negative breast cancer group

3.3.3. The impact of the TP53 sporadic mutations on survival outcomes in the triple-negative breast cancer group 33

4. DISCUSSION 36

4.1. The clinicopathological characteristics and survival outcomes of sporadic triple-negative, luminal A, luminal B HER2 negative breast .... 36 4.2. Triple-negative germline founder BRCAl mutations positive and negative breast cancers 41

4.3. The frequency and prognostic significance of TP53 sporadic mutations in the triple-negative breast cancer BRCAl carriers and non-carriers 46

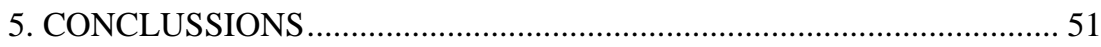

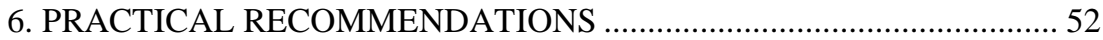

7. LIST OF PUBLICATIONS ON THE STUDY THEME .......................... 53

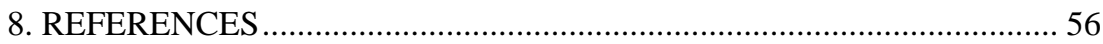




\section{LIST OF ABBREVIATIONS}

AC - Doxorubicin, cyclophosphamide

BRCA1 - Breast cancer susceptibility gene 1

BRCA2 - Breast cancer susceptibility gene 2

BCT - Breast-conserving therapy

CEF - Cyclophosphamide, epirubicin, 5-fluorouracil

CEP 17 - Centrometric Probe for chromosome 17

CK5/6 - Cytokeratin 5/6

CMF Cyclophosphamide, methotrexate, 5-fluouracil

DNA - Deoxyribonucleic acid

DRFS - Distant recurrence-free survival

EGFR - Epidermal growth factor receptor

ER - Oestrogen Receptor

FAC - 5-fluouracil, doxorubicin, cyclophosphamide

FFPE - Formaline-fixed paraffin-embedded

FISH - Fluorescence in situ hybridization

HER2/neu - Human Epidermal Growth Factor Receptor 2

IHC - Immunohistochemistry

LRR - Locoregional recurrence

LRFS - Locoregional recurrence-free survival

NCCN - The National Comprehensive Cancer Network

PARP - Poly (adenosine diphosphate) ribose polymerases

pCR - Pathologic complete response

PR - Progesterone Receptor 
SNP - The Single Nucleotide Polimorphism

TAC - Docetaxel, doxorubicin, cyclophosphamide

TP53 - Tumor protein 53 


\section{INTRODUCTION}

Triple-negative breast cancer is a heterogeneous clinicopathological entity defined as an oestrogen (ER), progesterone (PR) and HER2/ neu negative breast cancer [Bauer et al., 2007]. Triple-negative breast cancer is estimated as an immunohistochemical surrogate of basal-like breast cancer subtype, but it should be mentioned that there is no complete overlap between the two groups [Rakha et al., 2009]. Triple-negative breast cancer accounts for approximately 10-20\% of all breast cancer subtypes [Bauer et al., 2007]. As triple-negative breast cancer is hormone receptor and HER2/neu negative there is no targeted treatment available for this cancer subtype and a standard chemotherapy remains a basic systemic treatment option with no optimal cytotoxic regimen recommended. Inspite of relative chemosensitivity of this cancer subtype it is characterized by agressive clinical behavior with high recurrence and deaths rate, especially in the first five years after diagnosis [Carey et al., 2007]. Therefore, a further subclassification of triple-negative breast cancer is needed to develop a new targeted treatment to improve prognosis in these unfavorable cancer subtype.

In previous studies a strong relationship between BRCAl mutationassociated tumors and triple-negative breast cancer has been manifested, approximately $57-88 \%$ of all BRCA1-related tumours are triple-negative or/and basal-like [Foulkes et al., 2003; Reis-Filho et al., 2008]. The prevalence/incidence of germline $B R C A 1 / 2$ mutations in the triple-negative breast cancer subtype is relatively high, accounting for $10.6-19.5 \%$ in unselected patients' group [Gonzalez-Angulo et al., 2010; Evans et al., 2011]. BRCA1-mutated tumours carrier a dysfunctional DNA double-strand break repair mechanism and therefore is thought to be sensitive to platinum-based chemotherapy regimens and to inhibitors of the poly(ADP-rybosil)-polymerase [Kennedy et al., 2004; Farmer et al., 2005]. Theoretically, this agents could be 
a new treatment options also for triple-negative breast cancer subtype and at the moment several clinical trials are now underway to figure out a therapeutic benefit of DNA-damaging agents and PARP inhibitors in this breast cancer subtype [Silver et al., 2010]. The role of carrying a BRCA1 mutation could be crucial to guide a treatment strategy and to design further clinical trials.

However, previous studies showed contradicting and limited results with similar or worse outcomes for affected BRCA mutation carriers [StoppaLyonnet et al., 2000; Robson et al., 2004; Brekelmans et al., 2006; Rennert et al., 2007; Lee et a1., 2011; Bayraktar et al., 2011; Gonzalez-Angulo et al., 2011]. Other potential agent for targeted treatment could be p53 or components of the p53 signaling pathway [Turner et al., 2013]. Approximately $60-88 \%$ of triple-negative / basal-like or BRCAl-related breast cancers have TP53 mutations [Shah et al., 2012; Dumay et al., 2013]. Experimental models of breast cancer in mice revealed that tumors carrying TP53 mutations show more aggressive clinical behavior [Lang et al., 2004]. The clinical studies showed contraversial results about the predictive and prognostic value of p53 protein overexpression/ TP53 somatic mutations [Pharoah et al., 1999; Overgaard et al., 2000; Goffin et al., 2003; Olivier et al., 2006]. The majority of studies used immunohistochemistry(IHC) of $\mathrm{p} 53$ protein to detect alternations in the TP53 gene, but this method failed to provide sufficiently accurate results and demonstrated lower prognostic value, if compared with a complementary DNA(cDNA)-based sequencing [Sjorgen et al., 1996, Norberg et al., 1998]. According to the last update of recommenadations for use of tumor markers of the American Society of Clinical Oncology p53 measurements are not currently recommended for routine clinical practice [Harris et al., 2007]. Therefore, further investigation of the breast cancer subclass-specific prognostic and predicative potential of different types of BRCAl and TP53 mutations is required. 


\subsection{The aim of the research}

To investigate the prognostic significance of carrying a two germline BRCAl founder mutations (4153delA and 5382insC) and somatic TP53 mutations in patients with triple-negative breast cancer.

\subsection{Research objectives}

1. To evaluate the clinicopathological characteristics of the triplenegative $B R C A l$ founder mutations negative breast cancers.

2. To evaluate the locoregional recurrence (LRR) rate and the impact of the type of surgery on distant recurrence-free and breast cancerspecific survival in the triple-negative $B R C A l$ founder mutations negative group.

3. To evaluate the prognostic implication of carrying the BRCAl germline founder mutations among triple-negative breast cancer patients.

4. To identify prognostic factors for distant recurrence-free and breast cancer-specific survival in the triple-negative breast cancer group.

5. To evaluate the spectrum of somatic TP53 mutations and its impact on prognosis in the triple-negative breast cancer group.

\subsection{Scientific assumptions or working hypothesis}

Positive germline BRCAl founder mutation status and presence of somatic TP53 mutations may allow to identify the specific subsets of triplenegative breast cancer with different biological, prognostic features and response to treatment. 


\subsection{Scientific and practical novelty}

In our study we showed that positive BRCAl founder mutation status in the triple-negative breast cancer significantly improve prognosis and could be used as independent favorauble prognostic factor. Sporadic TP53 mutations could be used as prognostic factor for worse survival outcomes in the triplenegative breast cancer group.

\subsection{Personal contribution}

The author was involved in all stages of the study, including the study design, breast cancer diagnostic, surgery, postoperative patients management, multidisciplinary meetings. Clinical data collection from medical and pathological records, data annual update, data entering into electronic database, literature review, all stages of somatic TP53 mutations verification, scientific measurements, data statistical analysis were performed by the author.

\subsection{Ethics statement}

All patients gave their written informed consent for genetic testing. The study protocol was approved by the Ethical Commettee of Rīga Stradiņš University. 


\section{MATERIAL AND METHODS}

\subsection{The study design}

2943 patients $(\sim 50 \%$ of all breast cancer cases registered in Latvia between 2005-2011) with invasive breast cancer between 2005-2011 underwent genetic testing for BRCAl/2 mutations at the Rīga Stradinš University's Oncology Institute. In the study only patients who met all inclusion and exclusion criteria were included.

Inclusion criteria were:

1) invasive breast cancer in stage I-IV;

2) $\mathrm{ER}$ and PR defined as ER/PR - 0\%, HER2 - 0;1+; luminal A breast cancer, defined as ER/PR positive, HER2 - 0;1+, Ki-67 < 14; luminal B HER2 negative, defined as ER/PR positive, HER2 - 0;1+, Ki-67 $\geq 14$ [Hammond et al., 2010; Goldhirsch et al., 2011];

3) underwent definitive surgery between 2005-2011;

4) tested for $B R C A 1 / 2$ mutations;

5 ) in the case of positive BRCA1 germline mutation, only patients with two founder mutations (5382insC and 4153 delA) (Table 2.1.1.);

2.1.1. Table

Spectrum of $B R C A 1$ founder mutations included in the study

\begin{tabular}{|c|c|c|}
\hline BRCAl founder mutations & $\mathrm{N}=39$ & $(\%)$ \\
\hline 5382ins C & 29 & 74.4 \\
\hline 4153delA & 10 & 25.6 \\
\hline
\end{tabular}

6) signed informed consent forms to participate in the study;

7) available clinical data.

Exclusion criteria were: 
1) inflammatory breast cancers;

2) with a history of ovarian or other advanced cancers;

3) BRCA2 mutation carriers.

Consecutive 258 patients were deemed eligible for study.

The prospective phase of the study.

All patients were classified into four groups according to BRCAl mutation status and immunohistochemical subtypes of breast cancer defined at the 2011 St. Gallen Consensus [Goldhirsch et al., 2011] :

- 78 BRCA1 mutation negative triple-negative breast cancers operated in Riga Eastern Clinical University Hospital between 2005-2007 and in Pauls Stradins Clinical University hospital between 2005-2011;

- 86 BRCAl mutation negative luminal A breast cancers opereted in Pauls Stradins Clinical University hospital between 2005-2011;

- 56 BRCA1 mutation negative luminal B HER2 negative BRCA1 mutation negative breast cancers (Table 2.1.2.) opereted in Pauls Stradins Clinical University hospital between 2005-2011;

- 38 BRCA1 mutation positive triple-negative breast cancers opereted in Pauls Stradins Clinical University hospital, Riga Eastern Clinical University Hospital and Daugavpils Regional Hospital between 2005-2011. 
Expression of ER, PR, HER2 and Ki-67 in tumors of 78 BRCA1 mutation negative triple-negative breast cancer, BRCA1 mutation negative 86 luminal A, BRCA1 mutation negative 56 luminal $B$ HER2 negative and 38 BRCA1 mutation positive triple-negative breast cancer patients

\begin{tabular}{|c|c|c|c|c|}
\hline Characteristics & $\begin{array}{c}\text { BRCAl } \\
\text { negative } \\
\text { TNBC* }\end{array}$ & $\begin{array}{c}\text { BRCA1 } \\
\text { negative } \\
\text { Luminal A }\end{array}$ & $\begin{array}{c}\text { BRCA1 negative } \\
\text { Luminal B } \\
\text { HER2* negative }\end{array}$ & $\begin{array}{c}\text { BRCA1 } \\
\text { positive } \\
\text { TNBC }\end{array}$ \\
\hline ER* & $0 \%$ & $85.3 \%$ & $83.1 \%$ & $0 \%$ \\
\hline Average & $0 \%$ & $63.5 \%$ & $53.9 \%$ & $0 \%$ \\
\hline PR* & & & & $39(100 \%)$ \\
\hline Average & $78(100 \%)$ & $86(100 \%)$ & $56(100 \%)$ & $0(0 \%)$ \\
\hline HER2/neu* & $0(0 \%)$ & $0(0 \%)$ & $0(0 \%)$ & $0(\%)$ \\
\hline $0 ; 1+$ & $0(0 \%)$ & $0(0 \%)$ & $0(0 \%)$ & $58.4 \%$ \\
\hline $2+$ & $52.2 \%$ & $6.9 \%$ & $28.9 \%$ & \\
\hline $3+$ & & & & \\
\hline Ki-67 status & & & & \\
\hline Average & & & & \\
\hline
\end{tabular}

TNBC - Triple-negative breast cancer, ER - Oestrogen, PR - Progesterone, HER2/neu - Human epidermal growth factor receptor

The retrospective phase of the study: 66 triple-negative $B R C A l$ germline positive or negative breast cancer patients opereted in Pauls Stradins Clinical University hospital and Riga Eastern Clinical University Hospital between 2005-2011 with available paraffin-embedded blocks were included. 


\subsection{The pathological examination}

The prospective phase of the study:

258 breast cancer specimens from women undergoing surgery for primary invasive breast cancer between 2005-2011 in Pauls Stradins Clinical University Hospital, Daugavpils Regional Hospital and between 2005-2007 Riga Eastern Clinical University Hospital were collected. Tissue samples were fixed in $10 \%$ neutral buffered formalin. Tissue sample were processed and embedded in paraffin blocks. Histological parameters of all cases were reviewed by breast pathologists. Histological type and grade of ductal breast cancers was determined for each case according to the Bloom-Richardson histological system.

The retrospective phase of the study:

paraffin-embedded blocks were retrospectively obtained from Pauls Stradins Clinical University hospital and Riga Eastern Clinical University Hospital.

\subsection{Immunohistochemistry}

Estrogen (ER) and progesterone (PR) status and Ki-67 index were determined using standard immunohistochemistry (IHC). The evaluation of ER alpha and PR assays were performed according to the American Society of Clinical Oncology/ College of American Pathologists (ASCO/CAP) guideline recommendations for immunohistochemical testing of ER/PR. ER alpha and PR status were considered negative if immunoperoxidase staining of tumor cell nuclei was 0\% [Hammond et al., 2010].

The expression of ER, PR and proliferation marker Ki-67 was evaluated in the tumor cell nuclei. Ki-67 index below 14\% was considered as low and Ki-67 index equal or over 14\% was considered as high [Goldhirsch et al., 2011]. 
HER2/neu was assessed through IHC (Monoclonal Mouse Anti-Human HER2-pY-1248, Clone PN2A, Code Nr. M 7269). The assessment of HER2/neu expression was carried out using the HercepTest kit according to the manufacturer's instructions. IHC is scored on a qualitative scale from 0 to $3+$, based on interpretation of staining intensity, with 0 and $1+$ classified as negative ( 0 - was considered, if no staining or staining of the tumor cells membrane were less than $10 \%$, and $1+$, if more than $10 \%$ of the tumor cells membrane stained partly) and $3+$ classified as positive $(3+-$ was defined, as uniform intense membrane staining of $>30 \%$ of invasive tumor cells).

Specimens with equivocal HER2/neu IHC (2+) test results (a moderate complete membrane staining observed in more than $10 \%$ of the tumor cells), were confirmed by fluorescence in situ hybridization (FISH).

All IHC and FISH tests were performed in the Department of Pathology at Pauls Stradins Clinical University Hospital or/and Riga Eastern Clinical University Hospital.

\subsection{Molecular diagnostics}

\subsubsection{BRCA1/2 germline founder mutations}

$B R C A 1 / 2$ testing results were obtained from prospectively registered database of the Riga Stradins University's Oncology Institute. $230(89.1 \%)$ patients were tested for germline BRCAl founder mutations at the time of the surgery, $23(8.9 \%)$ patients were tested before surgery and $5(2 \%)$ patients were tested within 1 year after surgery. 


\subsubsection{Detection of sporadic TP53 gene mutations}

Purification of genomic DNA from FFPE tissue was performed using the QIAamp DNA FFPE Tissue Kit and Deparaffinization Solution. Somatic TP53 mutations were analysed in exons 5-8 using a RT-PCR assay with subsequent high resolution melt analysis (HRM). The reaction was run on Rotor Gene $6000^{\mathrm{TM}}$ real-time system (Qiagen, Germany). In the study method described by Krypuy et al., was used. HRM curve analysis was performed with Rotor-Gene Q Series Software 1.7. Mutations detected by RT-PCR/HRM were confirmed by DNA sequencing using Genetic Analyzer 3130 (Applied Biosystems) according to the standard protocol.

Data analysis was performed using Applied Biosystems software for DNA sequencing, SeqScape and NCBI BLAST. For interpretation of the results several databases were used: SNP-NCBI (National Center for Biotechnology Information), IARC TP53 (International Agency of Research on Cancer) and COSMIC (Catalogue of Somatic Mutations In Cancer).

\subsection{Data collection}

Clinical data were obtained from the patients' medical records and entered into electronic database. The data were completed at diagnosis and updated annually. Survival data were supplemented with Latvian cancer registry data-prospective database of Centre for Disease Control and Prevention.

\subsection{Follow-up}

The median follow-up from the original diagnosis until analysis was 36 ( range, 8-85) months in the triple-negative BRCAl mutation non-carriers, 41 
(range, 8-86) months in the triple-negative $B R C A 1$ mutation carriers, 45 (range, 24-96) months in the BRCAl negative luminal A group and 43 (range, 29-73) months in the BRCA1 negative luminal B HER2 negative group.

\subsection{Outcomes}

The outcomes were analysed in all 258 patients. The complete pathologic response (pCR) was defined as no evidence of residual invasive breast cancer and ductal carcinoma in situ both in the breast and lymph nodes. Locoregional recurrence (LRR) was defined as clinical and histological documented recurrence in the ipsilateral breast, chest wall or regional lymphnodes (axillary, supraclavicular, internal mammary). Locoregional recurrence-free survival (LRFS) was defined as the time from diagnosis to clinical and histological documented evidence of local recurrence. Distant recurrence was defined as clinical and radiographical evidence of distant relapse. Distant recurrence-free survival (DRFS) was defined as the time from diagnosis to first evidence of distant recurrence. The DRFS was censored at the data of the last follow-up if no distant recurrence were observed. The breast cancer-specific survival was calculated from data of diagnosis until death due to breast cancer.

\subsection{Statistical methods}

Statistical analysis was performed using the statistical software SPSS version 16.0. In the present study a chi-square, Fisher's exact test, independent samples t-test, one-way analysis of variance (ANOVA), univariate and multivariate Cox proportional hazards models were used. The breast cancerspecific survival was estimated using the Kaplan-Meier method and compared 
by a long-rank test. $\mathrm{P} \leq 0.05$ was considered to indicate a statistically significant difference. 


\section{RESULTS}

\subsection{The clinicopathological characteristics and estimates of survival outcomes in the triple-negative luminal A, luminal B HER2 negative breast cancers}

\subsubsection{The clinicopathological characteritics of sporadic triple-negative, luminal A, luminal B HER2 negative breast cancers}

The median age at diagnosis in the triple-negative breast cancer group was 54.3 years, in the luminal A breast cancer group the mean age at diagnosis was 60.1 years and in the luminal B HER2 negative breast cancer group the mean patients' age was 57.2. Patients in the triple-negative breast cancer group was statistically significantly younger than in the luminal A group $(\mathrm{P}<0.004)$.

The majority of triple-negative, luminal A and luminal B HER2 negative breast cancers were classified as ductal carcinomas. Triple-negative subgroup was more likely to have medullary breast cancer. Triple-negative breast cancer group was more likely to have grade III tumors than luminal A and B HER2 negative breast cancers. In the triple-negative breast cancer group there was a statistically significantly higher Ki-67 expression (52.2\%) compared to luminal A (6.9\%) and luminal B HER2 negative (28.9\%) breast cancer groups (P < $0.0001)$.

In the triple-negative breast cancer group the mean tumor size was a statistically significantly larger than in the luminal A breast cancer group (32.9 $\mathrm{mm}$ versus $23.8 \mathrm{~mm}$, respectively; $\mathrm{P}<0.002$ ). A statistically significantly higher proportion of patients in the luminal A breast cancer had T1 and T2 stage than in the triple-negative and luminal B HER2 negative breast cancers. The rate of lymph node negativity was statistically significantly higher in the luminal A subtype than in the triple-negative and luminal B HER2 negative subtypes. Luminal A breast cancers were more likely to be diagnosed in stage I 
than triple-negative and Luminal B HER2 negative breast cancers. A higher proportion of patients with triple-negative and luminal B HER2 negative breast cancer were diagnosed in stage III compared to luminal A breast cancer. There was a significantly positive correlation between tumor size and a positive lymph node status in the luminal A and B HER2 negative breast cancers. In contrast, in the triple-negative breast cancer group there was no correlation between tumor size and positive lymph node status $(\mathrm{P}=0.17)$ among patients with tumors of $<5 \mathrm{~cm}$, compare to luminal A and B HER2 negative $(\mathrm{P}<0.002$ and $\mathrm{P}<0.026$, respectively).

There was no statistically significant difference in performed type of surgery between breast cancer subtypes $(P=0.15)$. A statistically significantly higher proportion of patients in the luminal A breast cancer group underwent sentinel node biopsy, compare to patients in the luminal B HER2 negative and triple-negative breast cancer groups $(\mathrm{P}<0.02)$. A statistically significantly higher proportion of patients in the triple-negative breast cancer group received chemotherapy compare to luminal A and luminal B HER2 negative breast cancers. The chemotherapy regimens most commonly used in all breast cancer subtypes were anthracycline-based, anthracycline+taxane-based and CMF.

A significantly higher proportion of patients in the triple-negative group received neoadjuvant chemotherapy compare to luminal A and luminal B HER2 negative groups.

$63(80.8 \%)$ patients in the triple-negative breast cancer group, 51 (59.3\%) patients in the luminal A group and 39 (69.6\%) patients in the luminal B HER2 negative group received adjuvant radiation therapy $(\mathrm{P}<0.03)$. 


\subsubsection{Estimates of survival outcomes in the sporadic triple-negative, luminal A and luminal B HER2 negative breast cancer groups}

There was no statistically significant difference in the LRR rate between triple-negative, luminal A and luminal B HER2 negative groups (3 (3.9\%) versus $2(2.3 \%)$ versus $0(0 \%)$, respectively; $\mathrm{P}=0.34)$. The LRFS was 5.7 months (range, 4-8 months) in the triple-negative breast cancer group and 27.5 months (29 and 26 months) in the luminal A group.

A higher proportion of triple-negative breast cancer patients experienced distant recurrence compared with luminal A and luminal B HER2 negative breast cancer patients $(\mathrm{P}<0.0001)$. The DRFS was 32.2 months (range, 685 months) in the triple-negative breast cancer group, 45 months (range, 11-96 months) in the luminal A group and 42 months (range, 7-73 months) in the luminal B HER2 negative group. There was no statistically significant difference between groups in incidence of sites of distant recurrence.

Triple-negative breast cancer patients were more likely to die from breast cancer than Luminal A and luminal B HER2 negative breast cancer patients $(18(23.1 \%)$ versus $1(1.2 \%)$ and $3(5.4 \%)$ respectively; $\mathrm{P}<0.02)$. Luminal A and luminal B HER2 negative breast cancer patients had a statistically significant higher breast cancer-specific survival than non-carriers (98.8\% in the luminal A group, 94.6\% in the luminal B HER2 negative group and $76.9 \%$ in the triple-negative group, $\mathrm{P}<0.0001$ ) (Figure 3.1.2.2.).

In the univariate analyses, clinical $\mathrm{T}$ stage 3 and $4(\mathrm{HR}=2.445 ; 95 \%$ Cl:1.030-5.807; $\mathrm{P}<0.043)$ and positive lymph node status (HR $=2.405 ; 95 \%$ Cl:1.020-5.670; $\mathrm{P}<0.045)$ was associated with a higher risk of distant recurrence, no statistically significant effect of evaluated risk factors on breast cancer-specific survival was found (Figure 3.1.2.3.). 


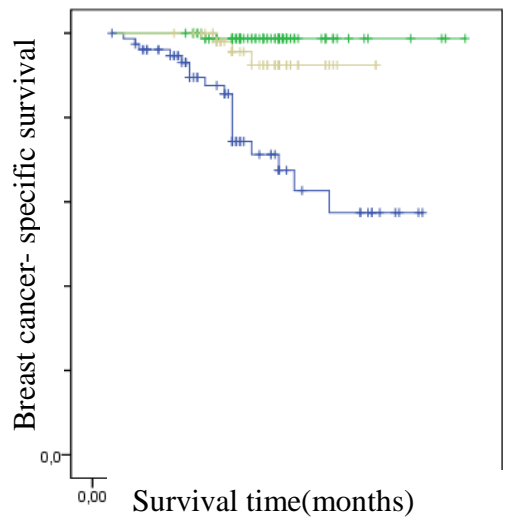

3.1.2.2. Figure. Survival curves of $B R C A 1$ negative triple-negative breast cancers (blue line), luminal A breast cancers (green line) and luminal B HER2 negative breast cancers (yellow line ). $P<0.0001$

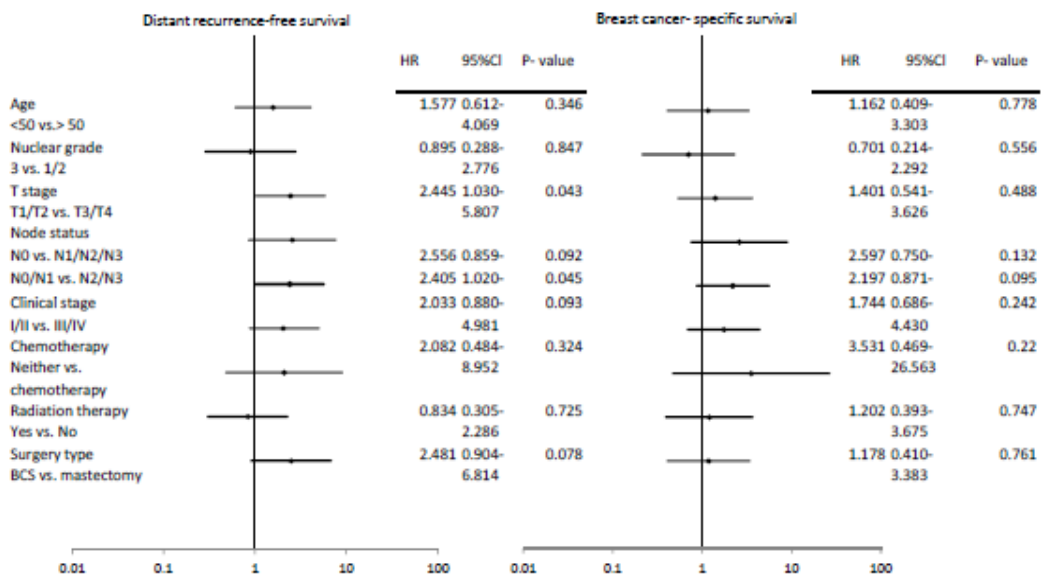

3.1.2.3. Figure. Univariate Cox proportional hazards model for distant recurrencefree survival and breast cancer-specific survival $\mathrm{HR}$ - hazard ratio, $\mathrm{Cl}$ - confidence interval, $\mathrm{BCT}$ - breast-conserving surgery 
In the multivariate analysis Cox proportional hazards model no statistically significant effect of evaluated risk factors on distant recurrence-free survival and breast cancer-specific survival was found (Figure 3.1.2.4.).

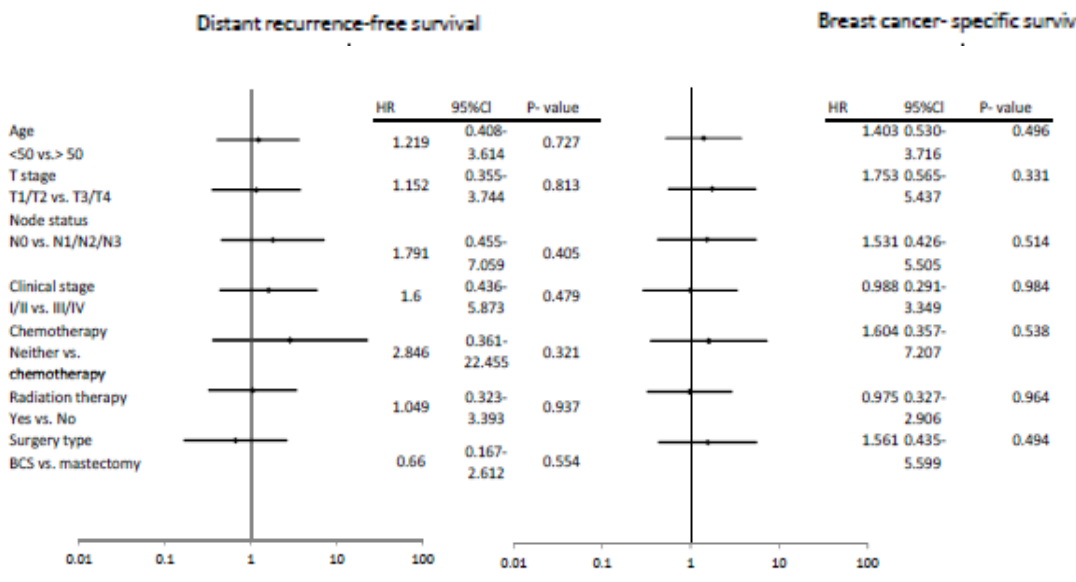

3.1.2.4. Figure. Multivariate Cox proportional hazards model for distant recurrence-free survival and breast cancer-specific survival $\mathrm{HR}$ - hazard ratio, $\mathrm{Cl}$ - confidence interval, $\mathrm{BCS}$ - breast-conserving surgery

\subsection{The clinicopathological characteristics and estimates of survival} outcomes in the triple- negative breast cancer $B R C A 1$ mutation carriers and non-carriers

\subsubsection{The clinicopathological characteristics of triple-negative breast cancer BRCA1 mutation carriers and non-carriers}

The median age at diagnosis in the triple-negative breast cancer $B R C A 1$ mutation positive group was 48.8 years compared to 54.3 years in the triplenegative BRCA1 mutation negative group $(\mathrm{P}<0.034)$.

Invasive ductal carcinoma was the most common histological type in both groups, but BRCAl mutation non-carriers were more likely to have 
invasive lobular carcinomas. The majority of triple-negative $B R C A 1$ mutation carriers and non-carriers were grade III tumors. There was no statistically significant difference in $\mathrm{Ki}-67$ expression between triple-negative BRCA1 mutation positive and negative breast cancer groups (59.8\% versus $52.2 \%$, respectively; $\mathrm{P}=0.27$ ).

The tumor size was $36.2 \mathrm{~mm}$ in the triple-negative BRCAl mutation positive group and $32.9 \mathrm{~mm}$ in the $B R C A 1$ mutation negative group $(\mathrm{P}=0.47)$. There was no statistically significant difference in relation to $\mathrm{T}$ stage and stage of the disease between two groups. There were a higher proportion of lymph node negative patients in the triple-negative BRCAl mutation-carriers group compared to non-carriers group $(\mathrm{P}<0.004)$.

There was no statistically significant correlation between tumor size and positive lymph node status among patients with tumors of $<5 \mathrm{~cm}$ both in the triple-negative $B R C A 1$ positive $(\mathrm{P}=0.079)$ and $B R C A 1$ negative groups $(\mathrm{P}=$ $0.17)$.

A higher proportion of triple-negative $B R C A l$ mutation carriers compared to BRCAl mutation non-carriers underwent mastectomy (32 (84.2\%) versus $42(53.9 \%)$, respectively; $\mathrm{P}<0.001)$. There were no difference in performed lymphadenectomy $(\mathrm{P}=0.80)$ and sentinel node biopsy $(\mathrm{P}=0.94)$ between triple-negative $B R C A 1$ mutation carriers and non-carriers.

There was no statistically significant difference between two groups in the proportion of patients, who received chemotherapy and the type of received chemotherapy regimens. The chemotherapy regimens used in the triplenegative BRCAl mutation carrriers and non-carriers were anthracycline-based, anthracycline+taxane-based, CMF, platine-based. 9 (23.7\%) of patients in the triple-negative $B R C A 1$ mutation carriers received neoadjuvant chemotherapy compared to $22(28.2 \%)$ in the triple-negative BRCAl mutation non-carriers ( $\mathrm{P}$ = 0.62). Triple-negative BRCAl mutation non-carriers more likely received radiation therapy compared to BRCAl mutation carriers (61 (78.2\%) versus 22 
(57.9\%), respectively; $\mathrm{P}<0.027) .3(3.9 \%)$ patients in the triple-negative $B R C A 1$ carriers group and $2(5.3 \%)$ patients in the BRCAl non-carriers group underwent bilateral salpingo-oophorectomy under the age of 50 years. Prophylactic mastectomy was performed in $3(7.7 \%) B R C A 1$ mutation carriers. Patients with positive BRCAl mutation experienced more bilateral breast cancers than non-carriers $(6(15.8 \%)$ versus $2(2.6 \%)$, respectively; $\mathrm{P}<0.016)$.

\subsubsection{Estimates of survival outcomes in the triple-negative $B R C A 1$ carriers and non-carriers}

There was no statistically significant difference in the LRR rate between BRCA1 mutation non-carriers and carriers (3 (3.9\%) versus 1 (2.6\%), respectively; $\mathrm{P}=0.80$ ). The LRFS was 5.7 months (range, $4-8$ months) in the BRCAl mutation non-carriers group and 20 months in the BRCAl mutation carriers group.

A higher proportion of $B R C A 1$ mutation non-carriers experienced distant recurrence compared with mutation carriers (22 (28.2\%) versus 4 $(10.5 \%)$, respectively; $\mathrm{P}<0.03)$. There was no statistically significant difference between the two groups in incidence of sites of distant recurrence. $B R C A 1$ mutation non-carriers were more likely to die from breast cancer than BRCA1 mutation carriers (18 (23.1\%) versus $2(5.3 \%)$, respectively; $\mathrm{P}<0.014)$. BRCA1 mutation carriers had a statistically significant higher breast cancerspecific survival than non-carriers $(94.9 \%$ in the BRCAl mutation carriers and $76.9 \%$ in the BRCA1 mutation non-carriers, $\mathrm{P}<0.02$ ) (Figure 3.2.2.1.). The development of bilateral breast cancer didn't significantly impact the survival outcomes $(\mathrm{HR}=0.040 ; 95 \% \mathrm{Cl}: 0.001-4.804 ; \mathrm{P}=0.59)$. 


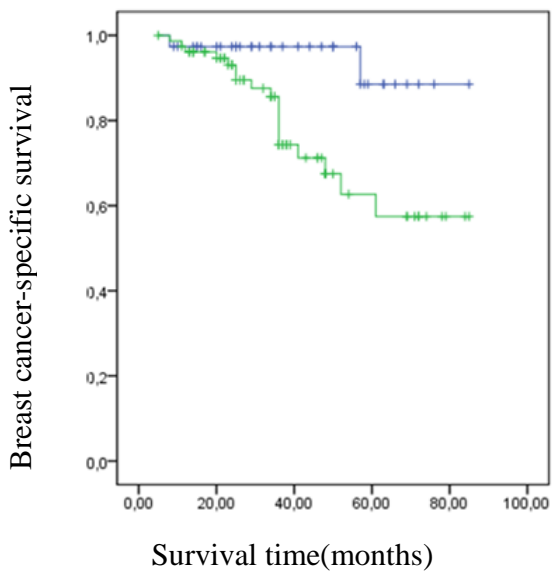

Figure 3.2.2.1. Survival curves of triple-negative $B R C A 1$ mutation carriers (blue line) and triple-negative $B R C A 1$ mutation non-carriers (green line). $P<0.02$

In the univariate analyses, clinical $\mathrm{T}$ stage 3 and $4(\mathrm{HR}=3.030 ; 95 \%$ Cl:1.194-7.688; $\mathrm{P}<0.02)$ and positive lymph node status $(\mathrm{HR}=4.694 ; 95 \%$ $\mathrm{Cl}: 1.358-16.219 ; \mathrm{P}<0.015)$ were associated with a higher risk of distant recurrence, but $B R C A 1$ positive status $(\mathrm{HR}=0.228 ; 95 \% \mathrm{Cl}: 0.052-0.997 ; \mathrm{P}<$ 0.049) was associated with deacreased risk of distant recurrence (Figure 3.2.2.2.).

In multivariate analysis Cox proportional hazards model BRCAl positive status was independent favorable prognostic factor for distant recurrence-free survival $(\mathrm{HR}=3.301 ; 95 \% \mathrm{Cl}: 1.102-9.893 ; \mathrm{P}<0.033)$ (Figure 3.2.2.3.). 


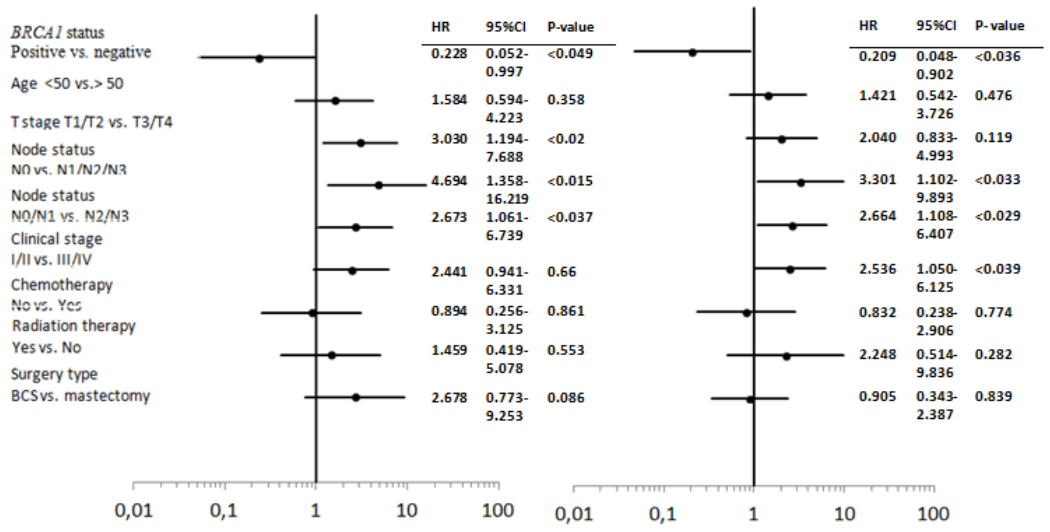

3.2.2.2. Univariate Cox proportional hazards model for distant recurrence-free survival and breast cancer-specific survival

$\mathrm{HR}$ - hazard ratio, $\mathrm{Cl}$ - confidence interval, BCT - breast-conserving surgery

In the univariate analyses, clinical stage III and IV (HR $=2.536 ; 95 \%$ Cl:1.050-6.125; $\mathrm{P}<0.039)$ and positive lymph node status $(\mathrm{HR}=3.301 ; 95 \%$ $\mathrm{Cl}: 1.102-9.893 ; \mathrm{P}<0.033)$ were associated with increased risk of breast cancer-specific death, but positive status $(\mathrm{HR}=0.209 ; 95 \% \mathrm{Cl}: 0.048-0.902 ; \mathrm{P}$ $<0.036)$ was associated with decreased risk of breast cancer-specific death (Figure 3.2.2.2.).

In the multivariate analysis Cox proportional hazards model no statistically significant effect of evaluated risk factors on breast cancer-specific survival was found (Figure 3.2.2.3.). 

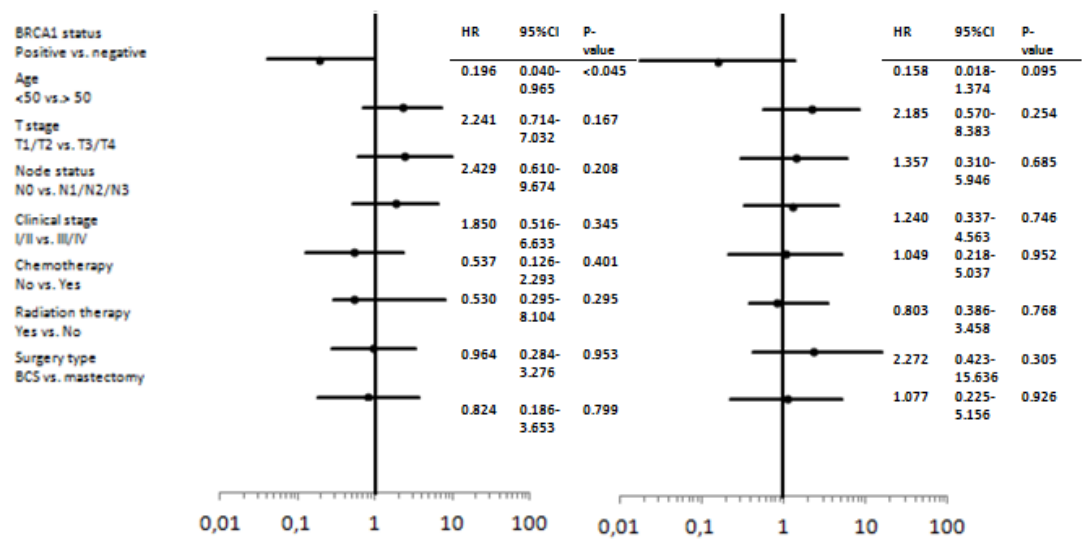

3.2.2.3. Multivariate Cox proportional hazards model for distant recurrence-free survival and breast cancer-specific survival

$\mathrm{HR}$ - hazard ratio, $\mathrm{Cl}$ - confidence interval, BCS - breast-conserving surgery

\subsection{Sporadic TP53 mutations in the triple-negative breast cancer}

\subsubsection{Spectrum of TP53 sporadic mutations in the triple-negative breast cancer BRCA1 germline mutations non-carriers and carriers}

A total of 66 primary triple-negative breast tumors were screened for mutations in TP53 exons 5 to 8 using real-time PCR with subsequent HRM and direct bi-directionally DNA sequencing performed on RT-PCR-positive specimens. TP53 sporadic mutations were found in 26 (39.4\%) tumors. There was no statistically significant difference in the TP53 mutations rate between triple-negative BRCA1 mutation non-carriers and carriers (22 (40\%) versus 4 (36.4\%), respectively; $\mathrm{P}=0.84)$.

In a total of 26 tumors with at least one TP53 sporadic mutation, 33 TP53 mutations $(27(81.8 \%)$ point mutations, 5 (15.2\%) deletions, 1 (3\%) insertion) were detected. Triple-negative breast cancers exhibited a high rates 
of $\mathrm{G}: \mathrm{C}>\mathrm{A}: \mathrm{T}(33.3 \%)$ mutations and $\mathrm{A}: \mathrm{T}>\mathrm{C}: \mathrm{G}$ (24.2\%) mutations. The distribution of the types of TP53 mutations are shown in Figure 3.3.1.1. There was no statistically significant difference in the types of TP53 mutations between triple-negative $B R C A 1$ carriers and non-carriers $(\mathrm{P}=0.29)$. There were $4(66.7 \%)$ transitions in the triple-negative $B R C A l$ carriers group compared to $15(55.6 \%)$ in the BRCAl non-carriers group $(\mathrm{P}=0.66)$. The triple-negative BRCAl carriers group harboured $1(16.7 \%)$ transversion mutation compared to $6(22.2 \%)$ in the BRCA1 non-carriers group $(\mathrm{P}=0.83)$. There was no insertions/deletions identified in the BRCAl carriers group compared to 6 (22.2\%) identified in the BRCAl non-carriers group $(\mathrm{P}=0.27)$.

In one triple-negative BRCA1 germline negative patient 3 different TP53 sporadic mutations ( 1 deletion, 1 transition, 1 transversion) in exons 5, 6 and 7 were detected. There was 5 (83.3\%) TP53 missense deleterious mutations in the triple-negative BRCA1 carriers compared to 11 (68.8\%) TP53 missense deleterious mutations in the BRCAl non-carriers group $(\mathrm{P}=0.08)$. A significantly higher proportion of TP53 mutations were detected in 8 exon compared to 7, 6 and 5 exons (15 (45\%) in exon 8 compared to 7 (21.2\%) in exon 7, $5(15 \%)$ in exon exon and $6(18.2 \%)$ in exon 5; P < 0.0017$)$. In the triple-negative BRCA1 carriers all 6 (100\%) TP53 mutations were identified in 7 and/or 8 exons compared to 16 (48.5\%) TP53 mutations in the non-carriers, but this difference didn't reach statisticall significance $(\mathrm{P}=0.067)$. We identified three novel sporadic TP53 mutations (c.510 ins TAG in exon5, c.446del $\mathrm{C}$ in exon 5 and c.864 delT in exon 8 which are not described in the COSMIC and IARC TP53 databases. 


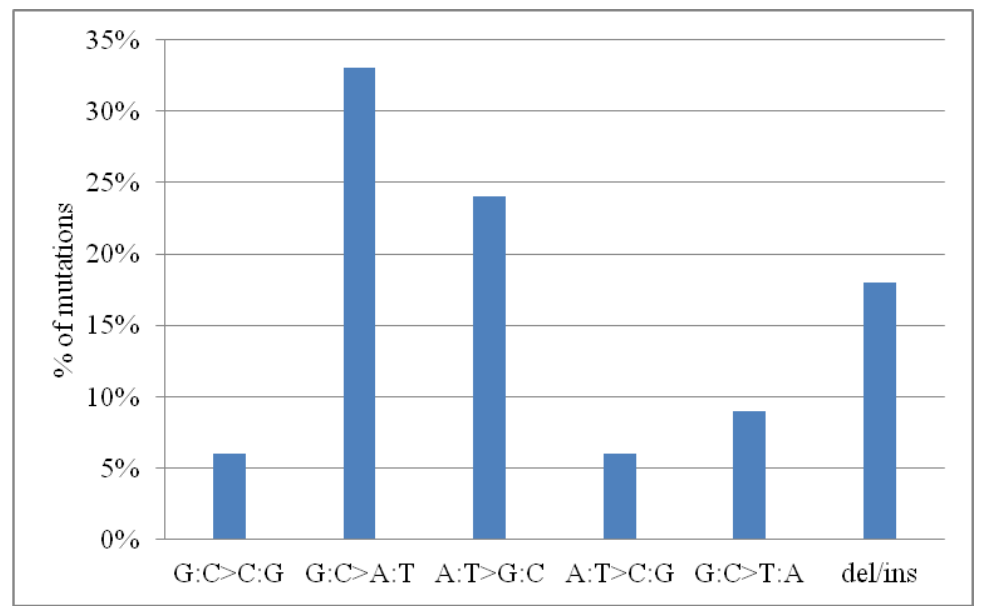

3.3.1.1.Figure. The types of the TP53 sporadic mutations in the triple-negative BRCAl carriers/non-carriers group

Del / ins - deletions / insertions

\subsubsection{The association between $T P 53$ sporadic mutations and clinicopathological characteristics in the triple-negative breast cancer group}

The median age at diagnosis in the triple-negative TP53 positive group was 53.3 years (range, 28-80 years) compared to 52.8 years (range, 31-79 years $)$ in the triple-negative TP53 negative group $(\mathrm{P}=0.88)$. There was no statistically significant difference in the size of the tumor between triplenegative TP53 positive and negative groups $(30.9 \mathrm{~mm}$ versus $33.6 \mathrm{~mm}$, respectively; $\mathrm{P}=0.28$ ). No statistically significant difference was found between triple-negative TP53 positive and negative group on percentage of cases of ductal $(18(6 \%)$ versus $32(80 \%)$, respectively; $\mathrm{P}=0.08)$ and lobular carcinoma (3 (11.5\%) versus $6(5 \%)$, respectively; $\mathrm{P}=0.72)$. A higher proportion of patients in the triple-negative TP53 positive group had a medullary carcinoma compared to TP53 negative group, but this difference 
didn't reach statisticall significance (3 (11.5\%) versus 1 (2.5\%), respectively; P $=0.19) .5(12.5 \%)$ patients in the triple-negative TP53 mutations negative group had a grade II and 27 (67.5\%) patients had a grade III tumors compared to $2(7.7 \%)$ patients with grade II tumors and $17(65.4 \%)$ patients with grade III tumors in the triple-negative TP53 positive group $(\mathrm{P}=0.60)$. In the triplenegative TP53 mutation positive group there was a higher ki-67 expression compared to triple-negative TP53 mutation negative group, but this difference was not statistically significant $(62.4 \%$ versus $54.7 \%$, respectively; $\mathrm{P}=0.325)$. There was no statistically significant difference between triple-negative TP53 positive and negative groups in relation to $\mathrm{T}$ stage, lymph node status and stage of disease (Table 3.3.2.1.)

3.3.2.1. Table

The histopathological features of the triple-negative breast cancers according to TP53 status

\begin{tabular}{|c|c|c|c|}
\hline Characteristics & $\begin{array}{c}\text { Triple-negative } \\
\text { TP53 positive } \\
\text { ne } 26 \\
\text { No. of patients }(\%)\end{array}$ & $\begin{array}{c}\text { Triple-negative TP53 } \\
\text { negative } \\
n=40 \\
\text { No. of patients }(\%)\end{array}$ & P-value* \\
\hline T stage & & & \\
\hline T1 & $6(23.1 \%)$ & $9(22.5 \%)$ & 0.95 \\
\hline T2 & $13(50 \%)$ & $23(57.5 \%)$ & 0.56 \\
\hline T3 & $6(23.1 \%)$ & $6(15 \%)$ & 0.43 \\
\hline T4 & $1(3.8 \%)$ & $2(5 \%)$ & 0.88 \\
\hline Nodal status & $13(50 \%)$ & $18(45 \%)$ & 0.73 \\
\hline N0 & $6(23.1 \%)$ & $9(22.5 \%)$ & 0.95 \\
\hline N1 & $2(7.7 \%)$ & $11(27.5 \%)$ & 0.052 \\
\hline N2 & $5(19.2 \%)$ & $2(5 \%)$ & 0.09 \\
\hline N3 & & & 0.29 \\
\hline Stage & $6(23.1 \%)$ & $5(12.5 \%)$ & 0.63 \\
\hline I & $12(46.1 \%)$ & $21(52.5 \%)$ & 0.89 \\
\hline II & $8(13.8 \%)$ & $13(32.5 \%)$ & 0.87 \\
\hline III & $0(0 \%)$ & $1(2.5 \%)$ & \\
\hline IV & & & \\
\hline
\end{tabular}

* Chi-square analysis 
$14(53.8 \%)$ patients in the triple-negative TP53 positive and $16(40 \%)$ patients in the triple-negative TP53 negative group underwent breastconserving surgery $(\mathrm{P}=0.29) .12(46.2 \%)$ patients in the triple-negative TP53 positive and $24(60 \%)$ patients in the triple-negative TP53 negative group underwent mastectomy $(\mathrm{P}=0.29)$. There was no statistically significant difference in performed lymphadenectomy (19 (73.1\% versus 32 (80\%), respectively)) and sentinel node biopsy (7 (26.9\%) versus 8 (20\%), respectively) between triple-negative TP53 positive and negative groups ( $\mathrm{P}=$ 0.53). There was no statistically significant difference in received chemotherapy regimens between two groups. The vast majority of patients both in the triple-negative TP53 positive and negative groups received anthracycline-based chemotherapy. There was no significant difference between triple-negative TP53 positive and negative group in received radiation therapy $(22(84.6 \%)$ versus $32(80 \%)$, respectively; $\mathrm{P}=0.66)$.

\subsubsection{The impact of the TP53 sporadic mutations on survival outcomes in the triple-negative breast cancer group}

There was no significant difference in the LRR rate between triplenegative TP53 positive and negative group (1 (3.9\%) versus 2 (5\%), respectively; $\mathrm{P}=0.87) .7(26.9 \%)$ patients in the triple-negative TP53 mutations positive group and 7 (17.5\%) patients in the triple-negative TP53 negative group experienced distant recurrences $(\mathrm{P}=0.38)$. There was no statistically significant difference between two groups in incidence of sites of recurrence $(P=0.76)$. There was no statistically significant difference in DRFS between triple-negative TP53 mutations positive and TP53 mutations negative groups $(\mathrm{P}=0.37$ ). The DRFS was 28.1 months (range, 8-63 months) in the triple-negative TP53 positive group compared to 33.5 months (range, 8-79 months) in the triple-negative TP53 negative group. There was no statistically 
significant difference in the number of deaths between triple-negative TP53 mutations positive and TP53 mutations negative groups (7 (26.9\%) versus 9 $(22.5 \%)$, respectively $(\mathrm{P}=0.68))$.

Deleterious TP53 mutations were associated with statistically significant negative impact on distant-recurrence-free survival (63.6\% versus $85.0 \%$, respectively; $\mathrm{P}<0.036$ ) (Figure 3.3.3.1.). TP53 deleterious mutations showed no statistically significant prognostic impact on breast cancer-specific survival. However, there was a tendency towards worse breast cancer-specific survival in the triple-negative TP53 deleterious mutations positive group compared to negative group ( $80 \%$ versus $77.3 \%$; $\mathrm{P}=0.65$ ) (Figure 3.3.3.2.).

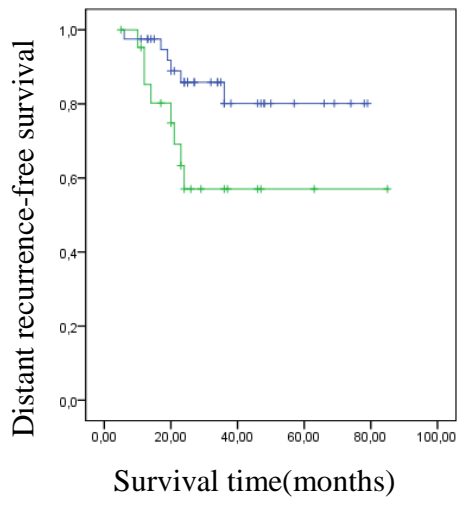

3.3.3.1.Figure. Distant recurrence-free survival ( DRFS) in the triple-negative TP53 sporadic deleterious mutations carriers (green line) and triple-negative TP53 sporadic deleterious mutations non-carriers (blue line). $P$ < 0.036

There was an insignificant tendency towards worse distant recurrencefree survival in the patients with deleterious mutations who were treated with anthracycline-based chemotherapy (61.5\% versus $85.7 \%$, respectively; $\mathrm{P}=0.13)$. 


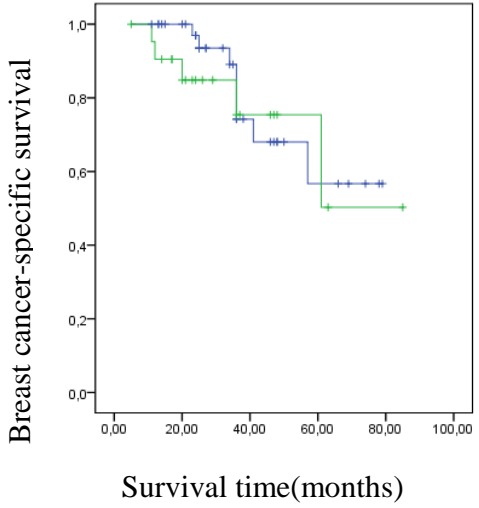

3.3.3.2. Figure. Survival curves of triple-negative TP53 sporadic deleterious mutations carriers (green line) and triple-negative TP53 sporadic deleterious mutations non-carriers (blue line). $P=\mathbf{0 . 6 5}$

However, positive TP53 deleterious mutations showed no significant impact on breast cancer-specific survival compared to negative group $(69.2 \%$ versus $82.1 \%$, respectively; $\mathrm{P}=0.74)$. 


\section{DISCUSSION}

\subsection{The clinicopathological characteristics and survival outcomes of sporadic triple-negative, luminal A, luminal B HER2 negative breast cancers}

According to our results the triple-negative breast cancer subtype is associated with significantly younger age at diagnosis compared to luminal A breast cancer subtype and a tend to younger age at diagnosis compared to luminal B breast cancer subtype. Similar results to our was published by Dent et al., where median age at diagnosis was 54.4 years for triple-negative breast cancer group compared to 57.7 years in the other group $(\mathrm{P}<0.0001)$ [Dent et al., 2007]. Liedtke et al., analysed 1.732 patients with triple-negative breast cancer and showed that younger age at diagnosis ( $\leq 40$ years) is associated with poor tumor differentiation and is an independent predictor of worse disease-free and overall survival despite more intense systemic treatment [Liedtke et al., 2013]. In contrast, our study showed no impact of patients' age at diagnosis on disease-free and breast cancer-specific survival both in the univariate and multivariate analysis.

The most frequent histological subtype in the triple-negative breast cancer group was ductal breast carcinoma (78.2\%). This results are in agreement with Carey et al., study there the majority of triple-negative breast cancer patients had a ductal carcinoma of no special type [Carey et al., 2007]. Vincent-Salmon et al., demonstrated that medullary breast carcinoma is a specific entity within the basal-like breast cancer subtype that is characterized by higher immunohistochemical expression of CK5/6 and distinct genetic alterations [Vincent-Salmon et al., 2007]. In our study medullary breast carcinoma was siginificantly more common in the triple-negative breast cancer group $(\mathrm{P}<0.02)$ than in the luminal $\mathrm{A}$ and luminal $\mathrm{B}$ breast cancer groups. 
Several studies demostrated a more favorable prognosis for medullary breast carcinomas [Marginean et al., 2010]. In our study the histological type didn't have statistically significant impact on distant recurrence-free and breast cancer-specific survival in the univariate and multivariate analysis. However, no patients with medullary breast carcinoma in the triple-negative breast cancer group experienced local, distant recurrence or death due to breast cancer in the median follow-up period of 26 months. Triple-negative breast cancer patients were more likely to have poorly differentiated tumors $(\mathrm{P}<0.0001)$ with higher Ki-67expression than in the luminal A and luminal B HER2 negative breast cancer subtype $(\mathrm{P}<0.0001) .83 .6 \%$ of triple-negative breast cancer patients were poorly differentiated (grade III) compare to $17.8 \%$ in the luminal A group and $47.9 \%$ in the lumunal B HER2 negative group. Similar results were published by several previous studies [Dent et al., 2007; Bauer et al., 2007; Onitilo et al., 2009]. Bauer et al., reported that $76 \%$ of triple-negative breast cancer patients have grade III tumors compared to only $28 \%$ in the other breast cancer group [Bauer et al., 2007]. In our study in the univariate analysis grade III failed to show to be a predictor of reduced distant recurrence-free and breast cancer-specific survival.

According to our study, the median tumor size is statistically significantly larger in the triple-negative breast cancer group than in the luminal A breast cancer group. This results are in concordance with previous studies [Dent et al., 2007; Bauer et al., 2007]. A statistically significantly lower proportion of patients had $\mathrm{T} 1$ and $\mathrm{T} 2$ breast cancer in the triple-negative breast cancer group (26.9\% and 48.7\%) compared to luminal A breast cancer group (60.5\% and 26.7\%). Similar results were published by Dent et al., there 36.5\% of triple-negative breast cancer patients had $\mathrm{T} 1$ tumors compared to $62.7 \%$ in the other breast cancer group [Dent et al., 2007]. There is a contraversial data reported about the frequency of axillary lymph node metastases at the time of diagnosis in the triple-negative breast cancer group [Reis-Filho et al., 2008]. 
Several studies demonstrated no statistically significant difference in lymph node positivity between triple-negative breast cancer group and other breast cancer groups [Rakha et al., 2009]. In contrast, other studies published a higher proportion of positive lymph nodes at the time of diagnosis in the triplenegative breast cancer group compared to other breast cancer group [Dent et al., 2007]. Our study similary to Tischkowitz et al., demostrated a lower rate of lymph node positive breast cancer patients in the triple-negative group compared to luminal A breast cancer group [Tischkowitz et al., 2007]. Furthermore, there was no significant correlation between tumor size and positive lymph node status in the triple-negative breast cancer patients with tumors smaller than $5 \mathrm{~cm}$ in diameter. Similar data were also reported by several previous studies [Dent et al., 2007; Foulkes et al., 2012 ]. In our study, in the univariate analysis T3/T4 stage versus T1/T2 and N2/N3 versus N0/N1 status showed weak positive predictive value of worse distant recurrence-free survival. However, $\mathrm{T}$ stage and lymph node status failed to show predictive value of breast cancer-specific survival in the univariate analysis and distant recurrence-free and breast cancer-specific survival in the multivariate analysis. Interestingly, Dent et al., reported no association of tumor size with distant recurrence and breast cancer-specific survival in the basal-like breast cancer group. However, there was a transient negative effect of size of the tumor on distant recurrence in the basal-like breast cancer group in a short period of time after the diagnosis. After 10 years survival rates were similar for patients with small and large basal-like tumors [Dent et al., 2009]. Therefore, in our study weak correlation between increasing tumor size and worse distant recurrencefree survival could be explained with relatively short median follow-up period of 36 months in the BRCAl negative triple-negative breast cancer group. According to our data triple-negative and luminal B HER2 negative breast cancer patients were less likely to be diagnosed in stage I than luminal A breast cancer patients $(38.5 \%, 41.9 \%$ and $70.9 \%$, respectively; $\mathrm{P}<0.0001)$. A 
statistically significantly higher proportion of triple-negative and luminal B HER2 negative breast cancer patients were diagnosed in stage III compared to luminal A breast cancer patients $(38.5 \%, 32.1 \%$ and $15.1 \%$, respectively; $\mathrm{P}<$ 0.0001). Similar results were presented by Bauer et al., there triple-negative breast cancer patients were significantly more likely to be diagnosed at more advanced stages [Bauer et al., 2007].

According to our study results, there was a tendency of increased risk of LRR in the triple-negative breast cancer group compared to luminal $\mathrm{A}$ and luminal B HER2 negative breast cancer groups, but these difference didn't reach statistical significance. In our study LRR rate in the triple-negative breast cancer group is lower than reported in other previous studies (3.9\% versus 8.8$21 \%$ in other studies) [Dent et al., 2007; Voduc et al ., 2010; Ho et al., 2012]. The median time to LRR was shoter in the triple-negative breast cancer group compared to luminal A breast cancer group (5.7 versus 27.5 months, respectively). Dent et al., reported similar results where was no statistically significant difference in the LRR rate between triple-negative and other breast cancer group with significantly shorter mean time to LRR in the triple-negative breast cancer group compared to other breast cancer group [Dent et al., 2007]. A study by Lowery et al., performed a meta-analysis of 15 studies there a total of 12.592 patients who underwent either BCT $(\mathrm{N}=7.174)$ or mastectomy $(\mathrm{N}=$ 5.418) were included. They concluded that triple-negative breast cancer patients have an increased risk of LRR regardless of the type of surgery (BCT $(\mathrm{RR}=0.49 ; 95 \% \mathrm{Cl}: 0.33-0.73)$ versus mastectomy $(\mathrm{RR}=0.66 ; 95 \% \mathrm{Cl}: 0.53-$ $0.83)$ ) compared to luminal breast cancer patients. In our study $36(46 \%)$ triplenegative breast cancer patients underwent breast-conserving therapy and 42 (54\%) patients underwent mastectomy. 2 (66.7\%) triple-negative breast cancer patients in the mastectomy group and 1 (33.3\%) patient in the breastconserving therapy group experienced LRR. A number of studies reported a significant improvement of locoregional control after more aggressive systemic 
treatment in the ER-negative and HER2-positive breast cancer patients [Fisher et al., 1996; Romond et al., 2005]. Therefore, in our study a relatively low rate of LRR in the triple-negative breast cancer group with no statistically significant difference compared to luminal A breast cancer group could be partially explained by high propotion of patients who received systemic therapy (69 $(88.5 \%))$. A higher proportion of triple-negative breast cancer patients experienced distant recurrence compared to luminal A and luminal B HER2 negative breast cancer patients $(28.2 \%$ versus $1.2 \%$ versus $5.4 \%$, respectively; $\mathrm{P}<0.0001)$. The DRFS was shoter in the triple-negative breast cancer group compared to luminal A and luminal B HER2 negative breast cancer groups (32.2 months versus 45 months and versus 42 months, respectively). There was a tendency to visceral metastases in the triple-negative breast cancer group compared to luminal A and luminal B HER2 negative breast cancer groups. Similar results were published by number of previous studies, where triplenegative breast cancer group showed increased likelihood of distant recurrence and was associated with increased risk of visceral metastases [Dent et al., 2007; Liedtke et al., 2008]. In our study triple-negative breast cancer patients had a significantly lower breast cancer-specific survival compared to luminal A and luminal B HER2 negative breast cancer patients $(76.9 \%$ versus $98.8 \%$ versus $94.6 \%$, respectively; $\mathrm{P}<0.0001)$. These results are in agreement with previously published data, where triple-negative breast cancer patients showed significantly lower overall and breast cancer -specific survival compared to luminal A and luminal B HER2 negative breast cancer patients [Dent et al., 2007; Liedtke et al., 2008].

Although, our median follow-up period of 3 years is relatively short, previous studies reported that the risk of any recurrence in the triple-negative breast cancer group is high in first 1-3 years after diagnosis with majorityof breast cancer-related events occuring within the first 5 years [Dent et al., 2007; 
Liedtke et al., 2008]. Thus, our follow-up period is quite adequate to distinquish the majority of treatment outcomes.

\subsection{Triple-negative germline founder $B R C A 1$ mutations positive and negative breast cancers}

The evidence from this study suggests that triple-negative breast cancer patients with germline BRCAl founder mutations (4153delA and 5382insC) and no evidence of ovarian cancer or other cancers in advanced stage have statistically significantly improved prognosis relative to non-carriers. We showed that positive $B R C A l$ mutation status statistically significantly reduce the risk of distant recurrence and breast cancer-specific death. After adjustment for age, $\mathrm{T}$ stage, nodal status, stage, surgery, radiation therapy and chemotherapy positive BRCAl mutation status was independent prognostic factor for lower distant recurrence risk.

So far there are only few studies published concerning the prognostic role of positive BRCA1 mutation status in the triple-negative breast cancer subtype. Contrary to our work results, these studies showed no significant difference in survival outcomes between triple-negative BRCAl mutation carriers and non-carriers [Lee et al., 2010; Bayraktar et al., 2011; GonzalezAngulo et al., 2011].

Lee et al., reported similar 5-years breast cancer specific and overall survival rates in both triple-negative $B R C A 1$ mutation carriers and non-carriers treated with alkylating chemotherapy $(\mathrm{HR}=0.64 ; \mathrm{P}=0.25)$ [Lee et al., 2010]. Gonzalez-Angulo et al., reported superior recurrence-free survival in the triplenegative BRCAl mutation positive patients compared to BRCAl mutation negative triple-negative breast cancer patients treated with surgery and anthracycline-taxane chemotherapy $(\mathrm{P}=0.031)$, but failed to demonstrate significant diference in overall survival $(\mathrm{P}=0.225)$ [Gonzalez-Angulo et al., 
2011]. Similarly, Bayraktar et al., showed no statistically significant difference in 5 year-overall survival rates between $B R C A 1 / 2$ mutation carriers and noncarriers [Bayraktar et al., 2011].

However, these studies have had some limitations: the cut-off levels for ER and PR negativity were not specified [Lee et al., 2010] or defined as nuclear staining $\leq 10 \%$ [Bayraktar et al., 2011], both groups were not homogenized by received chemotherapy regimens [Gonzalez-Angulo et al., 2011], missing information about accomponying cancers [Gonzalez-Angulo et al., 2011] or patients with previous ovarian cancer included in the study\%[ Bayraktar et al., 2011], no breast cancer-specific survival were evaluated [Gonzalez-Angulo et al., 2011] and prognostic significance of separate BRCAl mutations were not evaluated [Lee et al., 2010; Bayraktar et al., 2011; Gonzalez-Angulo et al., 2011].

In our study, the adoption of strict criteria of ASCO / CAP guideline recommendations for immunohistochemical testing of ER and PR (ER or PR are considered negative if $<1 \%$ of tumor cell nuclei are immunoreactive) to identify triple-negative breast cancer phenotype significantly diminished the number of triple-negative breast cancer cases included in the study [Hammond et al., 2010].

Although, our study data were based on relatively small number of cases, both groups were homogenious by tumor grade, the median tumor size, $\mathrm{T}$ stage, stage of the disease, received chemotherapy and only patients with two common germline founder BRCAl mutations (4153delA and 5382insC) were included in the study.

In previous studies, a different survival outcomes for various $B R C A 1$ germline mutations' variants were reported [Plakhins et al., 2011]. Plakhins et $a l$., reported a worse overall survival for breast cancer patients with positive BRCA1 4153delA mutation compared with 5382insC [Plakhins et al., 2011]. 
One more principal advantage of our study was that patients with ovarian cancer and other cancers in advanced stages were not included in the study population. Inspite of significantly better prognosis for BRCAl mutation carriers with ovarian cancer reported by Bolton et al., 5-years overall survival for these patients was only $46 \%$ [Bolton et al., 2012]. In all patients excluded from the study ovarian cancer was diagnosed in advanced stages (IIIC or IV) and all patients died from disseminated ovarian cancer within median period of 28.5 (range 6-45 months) months from the time of diagnosis. The risk of ovarian cancer is, approximately, $3 \%$ by the age of 40 years and $54 \%$ by the age of 60 years [Easton et al., 1995; Finch et al., 2012]. Several studies have shown a significant heterogeneity of breast and/ ovarian cancer prevalence among different mutations of BRCAl gene [Easton et al., 1995; Plakhins et al., 2011]. The prophylactic salpingo-oophorectomy reduces the penetrance of ovarian/ fallopian tube cancer by $75-96 \%$ and breast cancer by $53-56 \%$ [Finch et al., 2012] in patients with BRCA1 mutation. In addition, Bayraktar et al., showed that bilateral prophylactic oophorectomy allow statistically significantly reduce the risk for death in patients with triple-negative breast cancer $(\mathrm{HR}=0.01 ; 95 \%$ CI:0.01-0.69; P < 0.02) [Bayraktar et al., 2011].

A better breast-cancer specific survival in the triple-negative breast cancer BRCAl mutation carriers compared to non-carriers could be explained by biological differences and/ or higher sensitivity to chemotherapy. In our study $B R C A 1$ mutation carriers were statistically significantly younger than non-carriers (48.8 years versus 54.4 years, respectively; $\mathrm{P}<0.034$ ). Similar results to our study were published by number of studies [Lee et al., 2011; Gonzalez-Angulo et al., 2011]. Lee et al., reported a median age at diagnosis 39.9 (range, 28.1-73.4) years in the triple-negative BRCA1 mutation carriers group compared to 51.3 ( range, 28.1-75.6) years in the BRCA1 mutation noncarriers group $(\mathrm{P}<0.001)$ [Lee et al., 2011]. Gonzalez-Angulo et al., showed a median age at diagnosis 45 (range, 27-61) years in the triple-negative BRCAl 
mutation carriers compared to 53 (range, 28-83) years in the BRCA1 mutation non-carriers group $(\mathrm{P}<0.0051)$ [Gonzalez-Angulo et al., 2011]. In our study, there was no statistically significant difference in median age at diagnosis between triple-negative $B R C A 1$ mutation carriers and BRCAl mutation noncarriers younger than 50 years (40.1 years versus 40.2 years, respectively; $\mathrm{P}=$ 0.953). Similar to our study data, Bayraktar et al., showed no statistically significant difference in median age at diagnosis between triple-negative $B R C A 1$ mutation carriers and non-carriers younger than 50 years (41years (range, 22-71 years versus 40 years (range, 21-74 years), respectively; $\mathrm{P}=$ 0.74) [Bayraktar et al., 2011].

In the BRCAl carriers group compared to non-carriers group a higher proportion of node negative breast cancers were observed $(65.8 \%$ versus $37.2 \%$; $\mathrm{P}<0.004)$ with no statistically significant difference in $\mathrm{T}$ stage between two groups. Number of studies reported a similar data about the prevailing node-negativity in BRCA1 mutation carriers, even in those patients with large tumor size. These could be characterized as one of the main biological features of BRCA1 carriers [Eisinger et al., 1998; Chappuis et al., 2000; Foulkes et al., 2003; Brekelmans et al., 2005]. Tumor size and nodal status are independent prognostic factors for survival outcomes. In the univariate analysis T stage and nodal status as well as clinical stage were a strong predictors of outcomes. In the multivariate analysis this factors fail to predict outcomes in both triplenegative breast cancer BRCAl mutation carriers and non-carriers, may be due to relatively small study population. Similar to our study results, Brekelmans et $a l$., showed that both tumor size and nodal status have a strong prognostic impact on survival outcomes in the BRCAl mutation carriers. However, positive lymph node status was a weak prognoctic factor and had a significant impact on survival outcomes only if more than four lymph nodes were positive [Brekelmans et al., 2006]. In our study, there was no correlation between increasing tumor size and lymph node status among patients with tumors of $<5$ 
$\mathrm{cm}$ both in the triple-negative breast cancer BRCAl mutation carriers and noncarriers. In contrast, Brekelmans et al., showed strong correlation between tumor size and lymph node status [Brekelmans et al., 2006]. However, Foulkes et al., demonstrated no association between increasing tumor size and lymph node positivity in BRCAl mutation positive breast cancers. In addition, tumor size and nodal status were also a weak predictors of outcomes in BRCAl mutation carriers. The author proposed that this phenomenon could be associated with hematoganeous spread of these tumors [Foulkes et al., 2003; Foulkes et al., 2004].

A gene-expression signatures identified by Hedenfalk et al., allowed to differentiate between BRCA1-related and sporadic breast cancers. All of 7 $B R C A 1$-related tumors and 14 of 15 sporadic breast tumors were precise identified. Interestingly, that one sporadic breast cancer misclassified as BRCAl-related had a low level of BRCA1 expression due to BRCAl gene hypermethylation [Hedenfalk et al., 2001]. Van't Veer et al., identified 100 gene set that allowed to subclassify ER-negative breast tumors into BRCA1related and sporadic breast cancers [van't Veer et al., 2001]. In contrast, gene expression profile analysis performed by Sorlie et al., showed that BRCA1related tumors clustered together with basal-like breast cancers [Sorlie et al., 2003].

A higher chemosensitivity for BRCAl mutation positive breast cancer patients compared to sporadic breast cancer patients was proposed in previous studies [Robson et al., 2004; Rennert et al., 2007]. Rennert et al., reported a significantly better 10-year survival rates for BRCA1 mutation carriers than for non-carriers, who were treated with chemotherapy and no difference in survival rates among patients who didn't receive chemotherapy [Rennert et al., 2007]. Robson et al., showed better survival outcomes for BRCA1 mutation carriers, who received adjuvant chemotherapy compared to BRCAl mutation carriers, who received no adjuvant chemotherapy [Robson et al., 2004]. In our study 
$94.7 \%$ of patients in the BRCA1 mutation carriers group and $85.9 \%$ of patients in the BRCAl mutation non-carriers group received chemotherapy $(\mathrm{P}=0.30)$. Chemotherapy versus no chemotherapy both in the triple-negative BRCAl carriers and non-carriers failed to show statistically significant impact on distant recurrence-free and breast cancer-specific survival in the univariate and multivariate analyses. These results could be explained by a small number of patients in the triple-negative BRCAl carriers group (2(5.6\%)) and BRCA1 noncarriers group $(9(11.5 \%))$ who received no chemotherapy. Recently, similar results to our study was published by Narod et al., where 379 stage I breast cancer patients with $B R C A 1$ mutation carriers or patients with $B R C A 1$ mutation detected in a close blood relatives were included. 267 of 379 patients received chemotherapy. There was a statistically unsignificant tend towards a better 15years survival in women, who received chemotherapy compared to those with no chemotherapy $(89.4 \%$ versus $73.1 \%$, respectively; $\mathrm{P}<0.008)$. The difference in 15-years survival was statistically significant only in women with ER-negative breast tumors $(\mathrm{P}=0.02)$ [Narod et al., 2013].

There is a lack of prospective randomized trials comparing different chemotherapy regimens among $B R C A 1$ mutation carriers. According to the last ESMO clinical practice quidelines for management of $B R C A$ positive breast cancer patients, decisions about the chemotherapy in the BRCAl mutation carriers should be based on the same standard prognostic features as in the patients with wild-type and standard chemotherapy regimens are recommended [Balmana et al., 2010].

\subsection{The frequency and prognostic significance of $T P 53$ sporadic mutations in the triple-negative breast cancer $B R C A 1$ carriers and non-carriers}

The frequency of TP53 sporadic mutations varies across the studies and is mainly dependent on the techniques used to detect the mutation, screened 
coding region of the TP53 gene, definitions and methods used to identify basallike/triple-negative breast cancers, number of tumor samples analyzed and differences in quality of DNA extracted from formaline-fixed paraffinembedded (FFPE) or fresh-frozen tissue. The differences in assay techniques and study designs in other researches embarrass the interpretation and analysis of our results.

The majority of studies used IHC to detect mutant p53 protein accumulation in the cancer cell nuclei, because it is an inexpensive and easy to use in routine practice. However, the lower sensitivity and specificity of this method has been reported compared to cDNA sequencing method with relatively high false positive and false negative results and lower prognostic value ot this method [Sjorgen et al., 1996; Norberg et al., 1998; Manie et al., 2009 ]. Chaeng et al., reported a 40.2\% (13 of 32 cases) of p53 expression in the triple-negative breast cancer group defined by ER/PR and HER2 IHC statining. However, there was no difference in the p53 expression rate between triple-negative and non-triple-negative breast cancer groups $(40.2 \%$ versus 42.7\%) [Chaeng et al., 2009]. Ryu et al., showed similar results with $37.1 \%$ of triple-negative breast cancers overexpressing p53. The triple-negative breast cancers in this study was defined based on IHC assay with cut-off levels for ER and PR negativity $<10 \%$ of positive nuclear staining [Ryu et al., 2012 ]. In contrast, Ryu et al., demonstrated a higher p53 expression rate $(58.5 \%)$ in the triple-negative breast cancer group where 33 of 94 (35.1\%) patients had a basal-like breast cancer (defined by IHC staining for ER, PR, HER, CK 5/6, EGFR) and $61(64.9 \%)$ patients had a non-basal-like triple-negative breast cancer. However, there was no statistically significant difference in p53 overexpression between basal-like and non-basal-like triple-negative breast cancer patients (57.6\% versus 59.0, respectively; $\mathrm{P}=0.532)$ [Ryu et al., 2012].

Manie et al., where $89 \%$ (34 of 38 cases) TP53 sporadic mutations were identified in the group of BRCAl germline negative basal-like breast 
cancers and $83 \%$ (29 of 35 cases) TP53 sporadic mutations were identified in the group of BRCAl germline positive basal-like breast cancers using direct sequencing of the exons 2-11 coding regions in each sample [Manie et al., 2009].

In contrast, in our study $40 \%$ (22 of 55) of triple-negative BRCA1 gemline mutations negative breast cancers harboured at least one TP53 alternation. Our results could be explained by lower proportion of true basallike breast cancers in the group of triple-negative breast cancers defined by IHC assay. The previous studies demostrated that approximately $40-80 \%$ of all triple-negative breast cancers are basal-like [Carey et al., 2007; Rakha et al., 2009; Cheang et al., 2008].

Interestingly, that in our study there was also no statistically significant difference in the frequency of the TP53 sporadic mutations in the triple-negative $B R C A 1$ germline mutations positive and negative groups (4 of $11(36.4 \%)$ cases versus 22 of 55(40\%) cases, respectively; $\mathrm{P}=0.84)$.

In addition, in our study only exons 5-8 were screened for sporadic TP53 mutations. However, it has been proposed that approximately $90 \%$ of mutations occur this region [Pharoah et al., 1999].

In contrast, in our study we used real-time PCR with subsequent HRM and bidirectional direct DNA sequencing performed on RT-PCR-positive specimens. RT-PCR with subsequent HRM used as a scanning methodology diminishes the amount of sequencing required, therefore, optimizing the process of the TP53 mutations detection and making the process less timeconsuming and more cost-effective [Krypuy et al., 2007]. Krypuy et al., reported a $100 \%$ sensitivity and $100 \%$ positive predictive value for the RT-PCR with subsequent HRM [Krypuy et al., 2007].

There are no studies published so far where sporadic TP53 mutations prognostic significance in the triple-negative/basal-like breast cancer have been evaluated. However, there are few studies that evaluated the prognostic role of 
p53 overexpression in the triple-negative breast cancer [Chae et al., 2009; Jung et al., 2011; Biganzoli et al., 2011; Ruy et al., 2012]. Ryu et al., reported that p53 overexpression have no prognostic value in the triple-negative breast cancer group. However, in this study authors used a cut-off levels for ER/PR negativity of less than $<10 \%$ [Ryu et al., 2012]. In contrast, Jung et al., showed a statistically significant negative impact on disease-free survival in the lymph node negative triple-negative breast cancer group [Jung et al., 2011]. Others showed similar results with statistically significant difference in survival outcomes by p53 protein expression in the triple-negative breast cancer group, but not in the non-triple-negative breast cancer group [Chae et al., 2009]. In addition, it was reported that in the triple-negative breast cancer group p53 protein overexpression was associated with previolusly defined 'basal-like' cluster and associated with worse overall and event-free survival [Biganzoli et al., 2011]. cDNA-based sequencing method provides a more precise prognostic information than IHC [Sjorgen et al., 1996; Norberg et al., 1998].

Our study showed that positive status for deleterious TP53 mutations is associated with significantly worse distant recurrence-free survival ( $\mathrm{P}<$ 0.036). There was an insiginificant tendency towards worse breast cancerspecific survival in the triple negative TP53 deleterious mutations positive group compared to negative group ( $80 \%$ versus $77.3 \% ; \mathrm{P}=0.65)$. Very similar findings with our study was published by Fernandez-Cuesta et al. Authors concluded that TP53 positive status is not associated with worse survival outcomes in breast cancer patients. Only positive truncating TP53 mutations status was a significant prognostic factor for increased recurrence risk in the patients group treated with anthracycline or/and taxane-based chemotherapy $(\mathrm{HR}=3.21 ; 95 \% \mathrm{CI}: 1.740-5.935 ; \mathrm{P}<0.0002)$ [Fernandez-Cuesta et al., 2012]. Number of studies demostrated that tumors positive for TP53 mutations/ p53 overexpressing show worse survival outcomes compared to wild-type after treatment with anthracycline-based chemotherapy [Aas et al., 1996; Chae et al., 
2009]. In our study $81.1 \%$ of triple-negative breast cancer patients received anthracycline-based chemotherapy. However, in this patients group positive TP53 status or TP53 truncating mutations showed no statistically significant impact on distant recurrence-free or breast cancer-specific survival. Interestingly, that Betheau et al., reported that positive TP53 status and basallike breast cancer was an independent predictors of a pCR. Patients, who achieved pCR had a favorable prognosis and those with residual disease positive TP53 status predicted worse survival outcomes [Bertheau et al., 2007]. 


\section{CONCLUSIONS}

1. Sporadic triple-negative breast cancers are characterized by younger age at diagnosis, higher expression of ki-67, larger tumor size, higher proportion of poorly differentiated tumors, medullary breast cancers and tumors in an advanced stages, higher distant recurrence rate and worse breast cancerspecific survival compared to luminal A breast cancers.

2. Sporadic triple-negative breast cancer group is not associated with significantly higher LRR rate compared to luminal A sporadic breast cancer group and the type of surgery do not statistically significantly impact distant recurrence-free survival and breast cancer specific survival in the triple-negative sporadic breast cancer group .

3. Triple-negative germline $B R C A l$ founder mutations carriers are associated with axillary lymph node negativity and have statistically significantly improved distant recurrence-free survival and breast cancer-specific survival compared to non-carriers.

4. Positive BRCAl mutation status is the independent prognostic factor for lower distant recurrence-free survival risk.

5. Sporadic mutations in the TP53 gene are associated with worse distant recurrence-free survival in the triple-negative breast cancer 


\section{PRACTICAL RECOMMENDATIONS}

1. Positive germline BRCAl founder mutations (4153delA and 5382insC) status could be used as an independent prognostic factor for more favourable prognosis in the triple-negative breast cancer group.

2. We recommend to test all triple-negative breast cancer patients for BRCAI founder mutations (4153delA and 5382insC)

3. Sporadic TP53 mutations detection could be recommended to identify women with worse survival outcomes in the triple-negative breast cancer group 


\section{LIST OF PUBLICATIONS AND REPORTS ON THE STUDY THEME}

\section{SCIENTIFIC PUBLICATIONS-(4)}

1. Maksimenko J., Irmejs A., Nakazawa-Miklasevica M., Melbarde-Gorkusa I., Trofimovics G., Miklasevics E., Gardovslis J. The prognostic role of BRCAl mutation in patients with triple-negative breast cancer. Oncology letters 2014, 7(1):278-284.

2. Maksimenko J., Irmejs A., Trofimovics G., Miklasevics E. Breastconserving surgery in early-stage triple-negative breast cancer: is there a higher risk of locoregional recurrence? Acta Chirurgica Latviensis 2013, (1):11-14.

3. Maksimenko J., Liepniece-Karele I., Irmejs A., Trofimovics G. The clinicopathologic characteristics and prognostic significance of triple-negative breast cancer phenotype. Acta Chirurgica Latviensis 2011, 11(1):16-20.

4. Liepniece-Karele I., Maksimenko J.,Trofimovics G. Basal CK19 expression in triple-negative breast cancer. Collection of Scientific papers of Riga Stradins University 2011, P. 88-93.

\section{INTERNATIONAL THESES AND REPORTS-(10)}

1. Thesis. Maksimenko J., Irmejs A., Miklasevics E., Trofimovics G. BRCAI mutation in the Triple-negative Breast Cancer Group. Hereditary Cancer in Clinical Practice 2012, 10(Suppl 4): A15.

2. Thesis and poster presentation. Maksimenko J., Irmejs A., Trofimovics G., Miklasevics E. BRCAl mutation and its prognostic role in the triple-negative breast cancer(TNBC) subtype. 13th St.Gallen International Breast Conference. 13.-16. marts, 2013, St.Gallen, Šveice. Abstract book.

3. Thesis and poster presentation. Maksimenko J., Irmejs A., Trofimovičs G., Miklaševičs E. Breast-conserving surgery in early-stage triple-negative breast 
cancer: is there a higher risk of locoregional recurrence? $32^{\text {nd }}$ Congress of the European Society of Surgical Oncology. 19.-21. septembris, 2012, Valensija, Spanija. Abstract book, P. 262.

4. Thesis and poster presentation. Maksimenko J., Irmejs A.,Trofimovičs G., Miklaševičs E. Lobular Histology Shows Tendency of Higher Risk of Involved Margins After First Breast-Conserving Surgery. 8th European Breast Cancer Conference, Vīne, Austrija. Abstract book. P. 609.

5. Thesis and poster presentation. Maksimenko J., Reteris M., Irmejs A.,Trofimovičs G.Operable breast cancer in very young women, is there a difference? Breast cancer in young women conference. 8.-10. novembris, Dublina, İrija. The Breast 2012, 21 (Suppl 1). P. 030.

6. Thesis and poster presentation. Maksimenko J., Irmejs A., Trofimovičs G., Miklaševičs E. Prophylactic mastectomy in patients with hereditary breast and ovarian cancer syndrome. $7^{\text {th }}$ Congress of Baltic Association of Surgeons. 27.-29.septembris, 2012. Rīga, Latvija. Abstract book.

7. Thesis and poster presentation. Reteris M., Maksimenko J., Irmejs A., Trofimovičs G. Breast cancer in young women under 35 years of age. $7^{\text {th }}$ Congress of Baltic Association of Surgeons. 27.-29.septembris, 2012. Rīga, Latvija. Abstract book.

8. Thesis and poster presentation. Maksimenko J., Liepniece-Karele I., Kudaba I. The analysis of triple-negative breast cancer in th Riga Eastern Clinical University Hospital. $5^{\text {th }}$ Baltic Congress of Oncology. 13.-15.maijs, 2010. Rīga, Latvija. Abstract book, -44 lpp.

9. Thesis and oral presentation. Maksimenko J., Irmejs A., Trofimovičs G., Miklaševičs E. Is a triple-negative breast cancer a contraindication for breastconserving surgery? $7^{\text {th }}$ Congress of Baltic Association of Surgeons. 27.-29.septembris, 2012. Rīga, Latvija. Abstract book.

10. Oral presentation. Maksimenko J., Trofimovičs G., Irmejs A., Miklaševičs E., Melbarde-Gorkuša I. The prevalence of $B R C A 1$ mutation in triple-negative 
breast cancer. Eurasian Forum on Breast Cancer. 3.-4. septembris, 2011, Maskava, Krievija.

\section{LOCAL THESES AND PRESENTATIONS -(4)}

1. Thesis and oral presentation. Maksimenko J., Irmejs A.,Trofimovičs G., Miklaševičs E. The prognostic role of BRCAl mutation in patients with triple-negative breast cancer. Zinātniskā konference, Rīgas Stradiña universitāte. 21.-22.marts, 2013. Rīga, Latvija. Tēžu grāmata. - 244 lpp.

2. Thesis and oral presentation. Maksimenko J., Irmejs A.,Trofimovičs G., Miklaševics E. Better prognosis for BRCAl mutation carriers among triplenegative breast cancers. Zinātniskā konference, Rīgas Stradiņa Universitāte.29.30.marts, 2012. Rīga, Latvija. Tēžu grāmata. - 250 lpp.

3. Thesis and poster presentation. Maksimenko J., Reteris M., Irmejs A.,Trofimovics G. Operable breast cancer in very young women ( $<35$ years), is there a difference? 9. Zinātniskā konference, Rīgas Stradiṇa Universitāte. 29.-30.marts, 2012. Rīga, Latvija. Tēžu grāmata. - 251 lpp.

4. Thesis and poster presentation. Liepniece-Karale I., Maksimenko J. CK 19 imūnhistoḳīmija trīskārši negatīva krūts vēža gadījumā. Zinātniskā konference, Rīgas Stradiṇa universitāte. 18.-19.marts, 2010. Rīga, Latvija. Tēžu grāmata. - 265 lpp. 


\section{REFERENCES}

1. Aas T, Borresen AL, Geisler S, et al. Specific P53 mutations are associated with de novo resistance to doxorubicin in breast cancer patients. Nat Med, 1996; 2(7):811-814.

2. Balmana J, Diez O, Rubio IT, et al. BRCA in breast cancer: ESMO Clinical Practice Guidelines. Ann Oncol, 2011; 22(6):31-34.

3. Bauer KR, Brown M, Cress RD, et al: Descriptive analysis of estrogen receptor(ER)-negative, progesterone receptor(PR)-negative, and HER2-negative invasive breast cancer, the so-called triple negative phenotype: A population-based study from the california cancer registry. Cancer, 2007; 109(9): 1721-1728.

4. Bayraktar S, Gutierrez-Barrera AM, Liu D, et al: Outcome of triplenegative breast cancer in patients with and without deleterious BRCA mutaions. Breast Cancer Res Treat, 2011; 130:145-153.

5. Bertheau P, Turpin E, Rickman DS, et al. Exquisite sensitivity of TP53 mutant and basal cancers to a dose-dense epirubicincyclophosphamide regimen. PLoS Med, 2004; 4(3):e90.

6. Biganzoli E, Coradini D, Ambrogi F, et al. p53 status identifies two subgroups of triple-negative breast cancers with distinct biological features. Jpn J Clin Oncol, 2011; 41(2):172-179.

7. Bolton KL, Chenevix-Trench G, Goh C, et al. Association between BRCA1 and BRCA2 mutations and survival in women with invasive epithelial ovarian cancer. JAMA, 2012; 307(4):382-390.

8. Brekelmans CT, Tilanus-Linthorst MM, Seynaeve C, et al: Tumour characteristics, survival and prognostic factors of hereditary breast cancer from BRCA2-, BRCA1-and non-BRCA1/2 famielies as compared to sporadic breast cancer cases. B Eur J Cancer, 2007; 43:867-876. 
9. Carey LA, Dees EC, Sawyer L, et al: The triple negative paradox: primary tumor chemosensitivity of breast cancer subtypes. Clin Cancer Res, 2007; 13(8): 2329-2334.

10. Chae BJ, Bae JS, Lee A, et al. p53 as a specific prognostic factor in triple-negative breast cancer. Jpn J Clin Oncol, 2009; 89(4):217-224.

11. Chappuis PO, Nethercot V, Foulkes WD, et al: Clinico-pathological characteristics of BRCA1-and BRCA2-related breast cancer. Semin Surg Oncol, 2000; 18:287-295.

12. Cheang M, Chia SK, Tu D, et al. Anthracyclines in basal breast cancer: The NCIC-CTG trial MA5 comparing adjuvant CMF to CEF. J Clin Oncol, 2009; 27:519.

13. Dent R, Trudeau M, Pritchard KL, et al: Triple-negative breast cancer: clinical features and patterns of recurrence: clinical features and patterns of recurrence. Clin Cancer Res, 2007; 13(15):4429-4434.

14. Dent R, Wedad MH, Trudewau M, et al. Time to disease recurrence in th e basal-like breast cancers. Cancer, 2009; 115(21):4917-4923.

15. Dumay A, Feuqeas JP, Wittmer E, et al. Distinct tumor protein p53 mutants in breast cancer subgroups. Int J Cancer, 2013; 132(5):1227-1231.

16. Gonzalez-Angulo AM, Timms KM, Liu S, et al: Incidence and outcome of BRCA mutations in unselected patients with triple receptor-negative breast cancer. Clin Cancer Res, 2011; 17(5):1082-1089.

17. Easton DF, Ford D, Bishop DT, et al: Breast and ovarian cancer incidence in BRCA1-mutation carriers. Breast Cancer Linkage Consortium. Am J Hum Genet, 1995; 56(1):265-271.

18. Eisinger F, Nogues C, Birnbaum D, et al. Low frequency of lymphnode metastasis in BRCA1-associated breast cancer. Lancet, 1998; 351(9116):6113-6114. 
19. Evans DG, Howell A, Ward D, et al: Prevalence of BRCA1 and BRCA2 mutations in triple-negative breast cancer. J Med Gene,t 2011; 48:520-522.

20. Farmer H, McCabe N, Lord CJ, et al: Targeting the DNA repair defect in BRCA mutant cells as a therapeutic strategy. Nature, 2005; 434:917-921.

21. Fernandez-Cuesta L, Pakman C, Falagan-Lotsch P, et al. Prognostic and predictive value of TP53 mutations in node-positive breast cancer patients treated with anthracycline-or anthracycline/taxane-based adjuvant therapy: results from the BIG 02-98 phase III trial. Breast Cancer Res, 2012; 14:R70.

22. Finch A, Evans G, Narod SA, et al: BRCA carriers, prophylactic salpingo-oophorectomy and menopause: clinical management considerations and recommendations. Future Medicine, 2012; 8(5):543-555.

23. Fisher B, Dignam J, Mamounas EP, et al. Sequetial metotrexate and fluorouracil for the treatment of node-negative breast cancer patients with estrogen receptor-negative tumors: eight-year results form National Surgical Adjuvant Breast and Bowel Project (NSABP) B-13 and first report of findings from NSABP-19 comparing methotrexate and fluorouracil with conventional cyclophosphamide, metotrexate, and fluouracil. J Clin Oncol, 1996; 14(7):1982-1992.

24. Foulkes WD, Metcalfe K, Hanna W, et al: Disruption of the expected positive correlation between breast tumor size and lymphnode status in BRCA1-related breas carcinoma. Cancer, 2003; 98:1569-1577.

25. Foulkes WD, Grainge MJ, Rakha EA et al. Tumor size is an unreliable predictor of prognosis in basal-like breast cancers and does not correlate closely with lymph node status. Breast Cancer Res Treat, 2008; 117(1):199-204. 
26. Foulkes WD. Size surprize? Tumour size, nodal status, and outcome after breast cancer. Curr Oncol, 2012; 19(5):241-243.

27. Goffin JR, Chappuis PO, Begin LR, et al. Impact of germlina BRCA1 mutations and overexpression of p53 on prognosis and response to treatment following breast carcinoma: 10-year follow-up data. Cancer, 2003; 97:527-536.

28. Goldhirsch A, Wood WC, Coates AS, et al: Strategies for subtypesdealing with the diversity of breast cancer: highlights of the St Gallen International Expert Consensus on the Primary Therapy of Early Breast Cancer 2011. Ann Oncol, 2011; 28(8):1736-1747.

29. Hammond ME, Hayes DF, Dawsett W, et al: American Society of Clinical Oncology/ College of American Pathologists guideline recommendations for immunohistochemical testing of estrogen and progesterone receptors in breast cancer. J Clin Oncol, 2010; 28:2784-2795.

30. Harris L, Herbert F, Mennel R, et al. American Society of clinical Oncology 2007 Update of Recommendations for the Use of Tumor Markers in Breast Cancer. J Clin Oncol, 2007; 25:5287-5312.

31. Hedenfalk I, Duggan D, Chen Y, et al. Gene-expression profiles in hereditary breast cancer. N Engl J Med, 2001; 344(8):539-548.

32. Ho AY, Gupta G, King TA, et al. Favorable prognosis in patients with T1a/T1bN0 triple-negative breast cancers treated with multimodality therapy. Cancer, 2012; 118(20):4944-4952.

33. Jung SY, Jeong J, Shin SH, et al. Accumulation of $\mathrm{p} 53$ determined by immunohistochemistry as a prognostic marker in node negative breast cancer; analysis according to St Gallen consensus and intristic subtypes. J Surg Oncol, 2011; 103(3):207-211. 
34. Kennedy RD, Quinn JE, Mullan PB, et al: The role of BRCA1 in the celullar response to chemotherapy. J Natl Cancer Inst, 2004; 96:1659-1668.

35. Krypuy M, Ahmed AA, Etema D, et al. High Resolution melting for mutation scanning of TP53 exons 5-8. BMC Cancer, 2007; 7:168.

36. Lang GA, Iwakuma $\mathrm{T}$, Suh YA, et al. Gain of function of a p53 requires hot spot mutation in a mouse model of Li-Fraumeni syndrome. Cell, 2004; 119:861-872.

37. Lee LJ, Alexander B, Stuart JS, et al. Clinical Outcome of Triplenegative Breast Cancer in BRCA1 Mutaions Carriers and Noncarriers. Cancer, 2011; 117(14): 3093-3100.

38. Liedtke C, Mazouni C, Hess KR, et al. Response to neoadjuvant therapy and long-term survival in patients with triple-negative breast cancer. J Clin Oncol, 2008; 26(8):1275-1281.

39. Liedtke C, Hess KR, Karn T, et al. Tha prognostic impact of age in patients with triple-negative breast cancer. Breast Cancer Res Treat, 2013; 138(2):591-599.

40. Manie E, Vincent-Salomon A, Lehmann-Che J, et al. High frequency of TP53 mutation in BRCA1 and sporadic basal-like carcinomas but not in BRCA1 luminal breast tumors. Cancer Res, 2009; 69:663-671.

41. Marginean F, Rakha EA, Ho BC, et al. Histological features of medullary carcinoma and prognosis in triple-negative basal-like carcinomas of the breast. Mod Pathol, 2010, 23(10):1357-1363.

42. Narod SA, Metcalfe K, Lynch HT, et al. Should all BRCA1 mutation carriers with stage I breast cancer receive chemotherapy. Breast Cancer Res Treat, 2013; 138(1):273-279.

43. Norberg T, Lennerstrand J, Inganas M, et al. Comparison between p53 protein measurements using the luminometric immunoassay and immunohistochemistry with detection of p53 gene mutations using 
cDNA sequencing in human breast cancer. Int J Cancer, 1998; 79:376-383.

44. Olivier M, Langerod A, Carrierri P, et al. The clinical value of somatic TP53 gene mutations in 1.794 patients with breast cancer. Clin Cancer Res, 2006; 12:1157-1167.

45. Onitilo AA, Engel JM, Greenlee RT, et al. Breast cancer subtypes based on ER/PR and Her2 expression: comparison on clinicopathological features and survival. Clin Med Res, 2009; 7(1-2):4-13.

46. Overgaard J, Yilmaz M, Guldberg P, et al. TP53 mutation is an independent prognostic marker for poor outcome in both nodenegative and node-positive breast cancer. Acta Oncol, 2000; 39:327-333.

47. Pharoach PD, Day NE, Caldas C. Somatic mutations in the p53 gene and prognosis in breast cancer: a meta-analysis. Br J Cancer, 1999; 80:1968-1973.

48. Plakhins G, Iremjs A, Gardovskis A, et al. Genotype-phenotype correlations among BRCA1 4153delA and 5382insC mutation carriers form Latvia. BMC Medical Genetics, 2011; 12:147.

49. Rakha EA, Aleskandarany M, El-Sayed ME, et al. The prognostic significance of inflammation and medullary histological type in invasive carcinoma of the breast. Eur J Cancer, 2009; 45:1780-1787.

50. Reis-Filho JS, Tutt ANJ. Triple-negative tumours: a critical review. Histopathology, 2008; 52:108-118.

51. Rennert G, Bisland-Naggan S, Barnett-Griness O, et al: Clinical outcomes of breast cancer in carriers of BRCA1 and BRCA2 mutations. N Engl J Med, 2007; 357:115-123.

52. Robson ME, Chappuis PO, Satagopan J, et al. A combined analysis of outcome following breast cancer: differences in survival based on 
BRCA1/BRCA2 mutation status and administration of adjuvant treatment. Breast Cancer Res, 2004; 6:R8-R17.

53. Romond EH, Perez EA, Bryant J, et al. trastuzumab plus adjuvant chemotherapy for operable HER2-positive breast cancer. N Engl J Med, 2005; 353(16):1673-1684.

54. Ryu Dw, Lee CH. Outcome of triple-negative breast cancer in patients with or without markers regulating cell cycle and cell death. J Korean Surg, 2012; 83(4): 187-195.

55. Shah SP, Roth A, Goya R, et al. The clonal and mutational evolution spectrum of primary triple-negative breast cancers. Nature, 2012; 486(7403):395-399.

56. Silver DP, Richardson AL, Eklund AC, et al: Efficacy of neoadjuvant Cisplatin in triple-negative breast cancer. J Clin Oncol, 2010; 28(7):1145-1153.

57. Sjorgen $\mathrm{S}$, Inganas $\mathrm{M}$, Norberg $\mathrm{T}$, et al. The p53 gene in breast cancer: prognostic value of complementary DNA sequencing versus immunohistochemistry. J Natl Cancer Inst, 1996; 88(3-4):173-182.

58. Solassol J, Ramos J, Crapez E, et al. KRAS mutation detection in pared frozen and formalin-fixed parrafin-embedded (FFPE) colorectal cancer tissues. Int J Mol Sci, 2011; 12:1391-3204.

59. Sorlie T, Tibshirani R, Parker J, et al. Repeated observation of breast tumor subtypes in independent gene expression data. Proc Natl Acad Sci USA 2003, 100(14):8418-8423.

60. Stoppa-Lyonnet D, Ansquer Y, Dreyfus H, et al: Familial invasive breast cancer: worse outcome related to BRCA1 mutations. J Clin Oncol, 2000; 18:4053-4059.

61. Sirohi B, Arnedos M, Popat S, et al: Platinum-based chemotherapy in triple-negative breast cancer. Ann Oncol, 2008; 19:1847-1852. 
62. Silver DP, Richardson AL, Eklund AC, et al. Efficacy of neoadjuvant Cisplatin in triple-negative breast cancer. J Clin Oncol, 2010; 28:1145-1153.

63. Tischkowitz M, Brunet JS, Begin LR, et al. Use of immunohistochemical markers can refine prognosis in triple negative breast cancer. BMC Cancer, 2007; 109:25-32.

64. Turner N, Moretti E, Siclari O, et al. Targeting triple negative breast cancer: Is p53 the answer? Cancer Treat Reviews, 2013; 39:541-550.

65. van't Veer LJ, Hongyue D, van de Vijver MJ, et al. Gene expression profiling predicts clinical outcome of breast cancer. Nature, 2002; 415(6871):530-536.

66. Vincent-Salomon A, Gruel N, Lucchesi R, et al: Identification of typical medullary breast carcinoma as a genomic sub-group of basallike carcinomas, a heterogeneous new molecular entity. Breast Cancer Res, 2007; 9(2):R24.

67. Voduc KD, Cheang MC, Tyldesley S, et al. Breast cancer subtypes and the risk of local and regional relapse. J Clin Oncol, 2010; 28(10)1684-1691. 